FACULTY OF ECONOMICS AND APPLIED ECONOMIC SCIENCES

CENTER FOR ECONOMIC STUDIES

ENERGY, TRANSPORT \& ENVIRONMENT

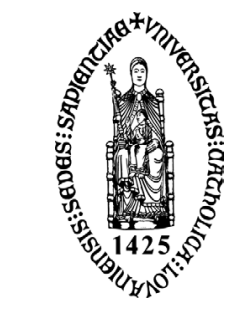

KATHOLIEKE UNIVERSITEIT LEUVEN

WORKING PAPER SERIES

$n^{\circ}$ 2003-18

\title{
New Roads to International Environmental Agreements: The Case of Global Warming*
}

\section{Johan Eyckmans (KU.Leuven - CES; EHSAL Europese Hogeschool Brussel) \\ Michael Finus (Department of Economics, University of Hagen)}

December 2003

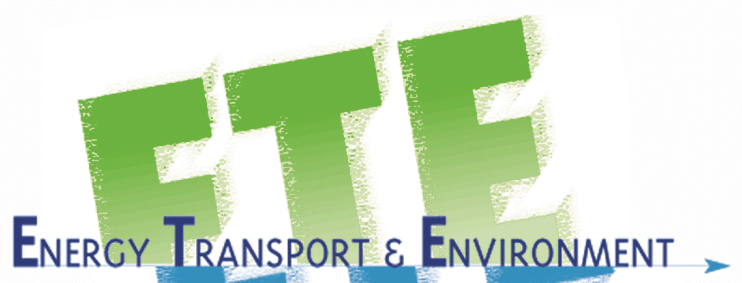

secretariat:

Isabelle Benoit

KULeuven-CES

Naamsestraat 69, B-3000 Leuven (Belgium)
tel:
+32 (0) 1632.66 .33
fax: $\quad+32(0) 1632.69 .10$

e-mail: Isabelle.Benoit@econ.kuleuven.ac.be http://www.kuleuven.be/ete 


\title{
New Roads to International Environmental Agreements: The Case of Global Warming ${ }^{*}$
}

First draft: August, 2003

\author{
Johan Eyckmans \\ K.U.Leuven, Centrum voor Economische Studiën, \\ Naamsestraat 69, B-3000 Leuven, Belgium \\ Johan.Eyckmans@econ.kuleuven.ac.be \\ Michael Finus \\ Department of Economics, University of Hagen, \\ Profilstr. 8, 58084 Hagen, Germany \\ Michael.Finus@fernuni-hagen.de
}

\begin{abstract}
We analyze with an integrated assessment model of climate change the formation of international environmental agreements (IEAs) by applying the widely used concept of internal\&external stability and several modifications of it. We relax the assumptions of a single agreement and open membership rule. It turns out that regional agreements are superior to a single agreement and exclusive is superior to open membership in welfare and ecological terms. Moreover, we show the importance of transfers for successful treaty-making. We relate our results to the design of current and past IEAs as well as to other issues of international policy coordination.
\end{abstract}

JEL-Classsification: C68, C72, H41, Q25

Keywords: design of climate treaty protocol, coalition formation, non-cooperative game theory

The authors acknowledge research assistants by Sebastian Binsch and Daniel Petzold. Both authors have greatly benefited from discussions with Carlo Carraro, Alfred Endres and Henry Tulkens. The title of this paper is inspired by Carraro (2000). 


\section{Introduction}

According to the Intergovernmental Panel on Climate Change (IPCC 2001) the enhanced greenhouse effect, caused by anthropogenic emissions of so-called greenhouse gases (GHGs) like carbon dioxide and methane, will negatively affect living conditions of current and future generations in almost all regions of the world. The enhanced greenhouse effect is a typical example of a global common problem. In every country, a multitude of fossil fuel users (cars, lorries, households, industries and farmers) emit GHGs that dissipate into the atmosphere where they mix uniformly. Since the global atmosphere is an open-access depository of GHGs, individual polluters have no incentive to internalize their climate change externalities. As it is well-known, this non-cooperative situation is not optimal from the global society's point of view (Cornes and Sandler 1996; Endres 1997, Tahvonen 1994 and Eyckmans et al. 1993). In order to reach a globally optimal solution, some kind of international coordination of climate policies is needed. However, economists are skeptical about the prospects of effective international policy coordination due to free-rider incentives and the lack of a supranational enforcement power.

The bulk of the environmental economics literature has been using non-cooperative game theory ${ }^{1}$ to explain the problems of forming coalitions by applying the concept of internal and external stability (I\&E-S; e.g., Barrett 1994, Carraro and Siniscalco 1993, Hoel 1992 and Rubio and Ulph 2001). It is assumed that countries forming an international environmental agreement (IEA), i.e., a non-trivial coalition ${ }^{2}$, coordinate their policies by jointly maximizing the aggregate welfare to their coalition. An IEA is said to be internally stable if none of its members wants to leave; it is externally stable if none of the outsiders wants to join it. A key result of this literature, which has been called a paradox by Barrett (1994), is that whenever cooperation (global optimum) would generate large global welfare gains compared to a noncooperative situation (Nash equilibrium), stable coalitions achieve only little. Moreover, it is pointed out that from participation one cannot conclude success of cooperation: small coalitions may achieve more than large coalitions in terms of global welfare and emission reduction. ${ }^{3}$

1 For a discussion about the differences between non-cooperative and cooperative game theory see Bloch (1997), Finus (2003a) and Finus and Rundshagen (2003b). For cooperative game theory approaches to IEAs see for instance Chander and Tulkens (1995) and (1997), Eyckmans and Tulkens (1999) and Funaki and Yamato (1999).

2 A non-trivial coalition is a coalition of at least two members.

3 For an overview of assumptions and results of game theoretical analyses of IEAs see Finus (2001 and 2003a). 
I\&E-S makes at least two implicitly assumptions that have been questioned by Carraro (1997) for the first time in the context of IEAs. First, I\&E-S restricts coalition formation to only one (non-trivial) coalition. That is, countries have only the option to join an agreement or to remain a non-signatory (singleton) but cannot group into different agreements. Clearly from a theoretical point of view, such a restriction is not satisfactory. The key questions are whether countries will form "regional agreements" instead of one "global agreement" if this assumption is given up and if so whether "multiple agreements" are superior to a "single agreement" in welfare or ecological terms. ${ }^{4}$ From the theoretically oriented literature (e.g., Carraro 2000, Carraro and Marchiori 2003, Finus 2001 and 2003b and Finus and Rundshagen 2003a) it appears that, indeed, in equilibrium multiple coalitions will emerge. However, those results have been derived under the assumption of symmetric (identical) players and welfare and ecological conclusions can only be derived for even more restrictive assumptions. Thus, it is the first objective of this paper to analyze the effect of single versus multiple coalition formation under more realistic assumptions, using data from an integrated assessment model of climate change. ${ }^{5}$

However, this issue has also an empirical dimension that may seem more controversial. On the one hand, one may argue that all IEAs that have been signed up to now are single agreements. There is only one Montreal Protocol that regulates CFCs (chloro-fluoro-carbons), one Oslo Protocol that aims at reducing sulfur emissions and only one Kyoto Protocol with the objective to mitigate global warming. On the other hand, at least for more recent protocols, it is evident that members are treated differently and that therefore these protocols may be interpreted as multiple coalitions agreements. ${ }^{6}$ For instance, the Kyoto Protocol distinguishes between Annex-B- and non-Annex B-countries where only the former group has agreed to quantified emission ceilings. Another example is the Montreal Protocol that makes special

4 "Regional or multiple agreements" means a coalition structure with multiple non-trivial coalitions and a "global or single agreement" is a coalition structure with only one non-trivial coalition where a coalition structure is a partition of $\mathrm{N}$ players. For details see section 2.

5 Integrated assessment models of climate change combine a stylized version of the world economy with a synthetic model of the global carbon cycle and climate and contain a full feedback of the physical environment on the economy. The seminal models in the field of climate change are DICE by Nordhaus (1993) and RICE by Nordhaus and Yang (1996).

6 This is different for "old IEAs" that typically require a uniform emission reduction by all participants. Examples include the Helsinki Protocol in 1985 on sulfur emission reduction (uniform reduction of $30 \%$ compared to 1980 emissions), the Sofia Protocol in 1988 on nitrogen oxides emission reduction (uniform requirement to freeze emissions at 1987 levels) and the Geneva Protocol in 1991 on the reduction of volatile organic compounds (uniform reduction of $30 \%$ compared to 1988 emission levels). 
provisions for developing countries, allowing for a longer transition period for compliance with abatement targets, exempting them from certain regulations and providing the option to draw on funds that are financed by developed countries.

Intuitively, we expect that allowing for the possibility to form multiple coalitions will increase the success of international pollution control. Regional agreements allow for more flexibility in coordinating different interests. Countries with similar interests will gather in a coalition. Hence, the free-riding problem will be less pronounced because of "homogenous coalitions". Some countries that would not join the global agreement because they find abatement efforts too ambitious might form a regional agreement with like-minded countries, implementing at least moderate abatement targets. Thus if no large single agreement is stable, small regional agreements may be a pragmatic second best solution.

The second assumption of I\&E-S is that of open membership, which follows from the definition of external stability. That is, countries can join an agreement without the consent of existing members. Hence, it is easy for outsiders to upset a potentially stable coalition, i.e., a coalition that is internally stable. Consequently from a theoretical point of view, it is evident that some form of exclusive membership may help to stabilize IEAs (e.g., Carraro and Marchiori 2003 and Finus and Rundshagen 2003a,c). Less evident is the question what "more stability" means in terms of welfare and ecological variables (emissions and concentration). Again, the theoretical literature can only provide partial answers since results have been derived under very restrictive assumptions (e.g., symmetric countries and static payoff structure). Thus, it is the second aim of this paper to analyze open versus exclusive membership based on more realistic assumptions, using data from an integrated assessment climate model.

From an empirical point of view, it is interesting to observe that currently all existing IEAs that deal with global environmental problems are of an open membership nature. For instance, the Kyoto Protocol does not require any voting before a new country can accede. However, other international institutions (that do not necessarily deal with global public goods or bads) require the consent of all their existing members before a newcomer can join. For instance, NATO (North Atlantic Treaty Organization) and WTO (Word Trade Organization) vote by unanimity on new members. Also the accession of ten new countries to the EU (European Union) had to be approved unanimously by the European Council, though approval in the European Parliament required only a simple majority. Thus, our modification of open membership may be interpreted as applying typical club good rules to the public good agreement IEA. 
In this paper, we focus on two extreme types of exclusive membership rules. The first rule assumes that only if 50 percent or more of the coalition members are in favor of accession, the potential entrant is allowed to join. We call this exclusive membership majority voting. The second rule assumes that only if all members agree to accession, an outsider is permitted to join. We call this exclusive membership unanimity voting. Other exclusive membership rules (e.g., 2/3 qualified majority rule) can be considered as intermediate cases but are not analyzed in this paper.

Taken together, we believe our paper extends previous work in three directions. Firstly, it is in the tradition of public choice theory that analyzes the effect of different voting procedures on the provision of public (or club) goods (see, in general for public good provision: Mueller, 2003 or Guttman, 1998. For IEAs in particular, see: Eyckmans 1999 and Finus and Rundshagen 1998). However, most of this work has been focusing on the level of public good provision, the choice of emission reduction targets or environmental policy instruments that is associated with decisions in the second stage of coalition formation. In contrast, we focus on different membership rules (single versus multiple coalitions and open versus exclusive membership) that are associated with the first stage of the coalition formation process in which countries decide on their participation (see section 2 for details).

Secondly, as mentioned above, our paper is inspired by recent developments in non-cooperative game theory that question fundamental assumptions of the traditional stability analysis of IEAs (e.g., Carraro 1997 and 2000). In contrast to this literature that has assumed symmetric countries, we analyze those issues based on a data set derived from an integrated assessment climate model. Thirdly, our paper is in the tradition of the literature that empirically tests stability of climate coalitions (e.g., Bosello et al. 2001, Botteon and Carraro 1997, Buchner et al. 2002, Finus et al. 2003 and Tol 2001). In contrast to the bulk of this literature, we pay more attention to the game theoretic underpinning of our model, consider modification of standard stability concepts and use an integrated assessment climate model that captures all important dynamic aspects of the greenhouse gas problem.

In the following, we lay out the game theoretical setting in section 2 and describe the empirical module of our model in section 3. Stable coalition structures are reported and evaluated in section 4. Section 5 summarizes our main findings and concludes with some final remarks. 


\section{The Game Theoretic Background of Coalition Formation}

\subsection{The Two-Stage Game}

Coalition formation is modeled as a two-stage game. In the first stage players (i.e., countries or regions) decide on their membership in a coalition, in the second stage coalition members choose their economic strategies.

\section{First Stage}

The decision in the first stage is modeled as a coalition game. Its definition comprises three elements: 1) the set of players $I=\{1, \ldots, N\}$ with a particular player denoted by index $\mathrm{i}$ or $\mathrm{j}$, 2) the set of coalition (or, alternatively, announcement) strategies $\Sigma=\Sigma_{1} \times \Sigma_{2} \times \ldots \times \Sigma_{\mathrm{N}}$ with a particular strategy of player $i \in I$ denoted by $\sigma_{i} \in \Sigma_{i}$, and 3) a coalition function $\psi$ that maps membership strategies $\sigma=\left(\sigma_{1}, \ldots, \sigma_{\mathrm{N}}\right)$ into coalition structures, $\psi: \Sigma \rightarrow \mathrm{C}: \sigma \mapsto \psi(\sigma)$. A coalition structure $\mathrm{c}=\left(\mathrm{c}^{1}, \ldots, \mathrm{c}^{\mathrm{M}}\right)$ is a partition of players where a particular coalition is denoted by $\mathrm{c}^{\mathrm{k}}, \mathrm{k} \in\{1, \ldots, \mathrm{M}), \mathrm{c}^{\mathrm{k}} \cap \mathrm{c}^{1}=\varnothing \forall \mathrm{k} \neq 1, \cup \mathrm{c}^{\mathrm{k}}=\mathrm{I}$ and $\mathrm{c} \in \mathrm{C}$ where $\mathrm{C}$ is the set of all possible coalition structures.

We consider two coalition games in the spirit of Yi and Shin's (1995) open membership game that we call single and multiple coalition game. The single coalition game captures the notion that players can only choose between strategy $\sigma_{i}=0$ that means "I do not want to sign the agreement" and $\sigma_{i}=1$ that means "I want to sign the agreement". More formally, we have:

\section{Definition 1: Single Coalition Game (SCG)}

a) The set of coalition strategies of player $i \in I, I=\{1, \ldots, N\}$, is given by $\Sigma_{i}=\{0,1\}$ where a particular strategy $\sigma_{i}$ is an announcement of an address.

b) Let $c^{i}$ denote the coalition to which player $i$ will belong. Coalition function $\psi^{S C G}$ maps strategy vector $\sigma$ into coalition structure $c$ as follows:

$c^{i}=\left\{\begin{array}{l}\{i\} \text { if } \sigma_{i}=0 \\ \left\{j / \sigma_{j}=1\right\} \text { if } \sigma_{i}=1\end{array}\right.$.

In order to capture the possibility that players can form multiple or regional agreements, we have to increase the number of coalition strategies. Since the maximum number of coalitions is $\mathrm{N}$ (all players form a singleton coalition), the strategy set must comprise now $\mathrm{N}$ instead of only two strategies. In terms of the coalition function we have to ensure that those players that have made the same announcement will form one coalition. Thus, we have: 


\section{Definition 2: Multiple Coalition Game (MCG)}

a) The set of coalition strategies of player $i \in I, I=\{1, \ldots, N\}$, is given by $\Sigma_{i}=\{1, \ldots, N\}$ where a particular strategy $\sigma_{i}$ is an announcement of an address.

b) Let $c^{i}$ denote the coalition to which player $i$ will belong. Coalition function $\psi^{M C G}$ maps strategy vector $\sigma$ into coalition structure $c$ as follows:

$c^{i}=\{i\} \cup\left\{j / \sigma_{i}=\sigma_{j}\right\}$.

From Definition 1 and 2 it is evident that the outcome of the coalition game will be a coalition structure of the form $c=\left(c^{1}, \ldots, c^{M}\right)$. In the case of the MCG, coalitions $c^{2}, \ldots, c^{M}$ may be non-trivial coalitions whereas in the SCG they are always singletons. If $\mathrm{M}=\mathrm{N}$ (each player is in a singleton coalition), this corresponds to the singleton coalition structure and if $\mathrm{M}=1$ (all players are in one coalition), this is called the grand coalition.

\section{Second Stage}

The decision in the second stage depends on the rules how players choose their economic strategies that follow from the definition of the valuation function. The valuation function $\mathrm{v}(\mathrm{c})$ maps coalition structures into a vector of individual payoffs (i.e., welfare) via an instruction how players choose their economic strategies $s_{i} \in S_{i}$, with $S=S_{1} \times S_{2} \times \ldots \times S_{N}$, for a given coalition structure $\mathrm{c}$. Hence, the valuation function is a composition of two functions $\mathrm{v}=\mathrm{W} \circ \varepsilon$ where $\varepsilon: \mathrm{C} \rightarrow \mathrm{S}: \mathrm{c} \mapsto \varepsilon(\mathrm{c})$ is a function mapping coalition structures into economic strategies and $\mathrm{w}: \mathrm{S} \rightarrow \mathbb{R}^{\mathrm{N}}: \mathrm{s} \mapsto \mathrm{w}(\mathrm{s})$ is a function mapping economic strategies into welfare levels.

More specifically, let the welfare function of player $i$ in the global warming game be given by $\mathrm{w}_{\mathrm{i}}(\mathrm{s})$ where $\mathrm{s}$ is a vector of economic strategies. That is, welfare of player $\mathrm{i}$ depends on his own strategy $s_{i}$ and those of other players, $s_{-i}$. The exact relationship between economic strategies (e.g., emission abatement and capital investment) and welfare as well as the elements in players' welfare function will be outlined in section 3. For the valuation function mapping coalition structures into payoffs - we make the following standard assumptions (Bloch 1997 and Yi 1997):

\section{Definition 3: Valuation Function}

Fix a coalition structure $c=\left(c^{l}, \ldots, c^{M}\right)$, let $v(c)=\left\{v_{i}(c)\right\}_{i \in I}=\left\{w_{i}(\varepsilon(c))\right\}_{i \in I}=\left\{w_{i}\left(s^{*}\right)\right\}_{i \in I}$ and assume for instruction $\varepsilon$ that all players belonging to a coalition $c^{k} \in c$ jointly maximize the aggregate payoff to their coalition. Let $s^{k}$ denote the economic strategy vector of coali- 
tion $c^{k}$ and $s^{-k}$ the economic strategy vector of all other coalitions $c^{l} \in c, l \neq k$, and assume that equilibrium economic strategy vector $s^{*}=\varepsilon(c)$ for coalition structure c satisfies:

$\forall c^{k} \in C, \forall s^{k} \in S^{k}: \sum_{i \in c^{k}} w_{i}\left(s^{*}\right) \geq \sum_{i \in c^{k}} w_{i}\left(s^{k}, s^{-k^{*}}\right)$ where $s^{*}$ is a unique interior equilibrium.

Definition 3 implies that the valuation of player $i, v_{i}(c)$, is identified by the entire coalition structure $\mathrm{c}$ and not only by the coalition to which he belongs. Players behave cooperatively within their coalition but non-cooperatively against players belonging to other coalitions when choosing their economic strategies. Put differently, members of a non-trivial coalition act as one single player maximizing the aggregate welfare to their coalition and coalitions play a Nash strategy in terms of economic strategies. Hence, economic strategies within a coalition are chosen efficiently. Consequently, the singleton coalition structure (grand coalition) implies an equilibrium economic strategy vector corresponding to the "classical" Nash equilibrium (social optimum). Thus, the highest global welfare will be obtained in the grand coalition, and any welfare level below that in any other coalition structure. Hence, inefficiencies in policy coordination must solely stem from the fact that countries do no form the grand coalition in the first stage of coalition formation since within coalitions economic strategies are efficiently chosen in the second stage.

Definition 3 implicitly assumes no transfers. This is one option that we consider in our simulations below, which we call the "no transfer case". Alternatively, we consider a second option to which we refer to as the "transfer case". Of course, there are many possibilities how the gains of cooperation could be distributed among coalition members as for instance the Shapley value (Barrett 1997, Botteon and Carraro 1997) or the Chander/Tulkens' transfer scheme (Chander and Tulkens 1997). We restrict ourselves to a modified version of the last transfer scheme of which the details will be laid out in section 3. At this stage, it suffices to point out that this transfer scheme assumes a particular rule how the surplus from cooperation within a coalition is distributed. Hence, $\hat{v}_{i}(c)=v_{i}(c)+t_{i}$ where $t_{i}>0$ implies that a player receives a transfer and $t_{i}<0$ that a player pays a transfer.

\subsection{Stability in the Reduced Stage Game}

For the properties of the welfare function that we define in section 3 it turns out that $\mathrm{s}^{*}$ is unique and lies well within the boundaries of the economic strategy space. Thus, there is a unique valuation (vector of individual payoffs) that is associated with each coalition structure $\mathrm{c} \in \mathrm{C}$. Consequently, the entire coalition formation process can be reduced to one single stage. This reduced stage game looks as follows: each player chooses his/her coalition strategy, $\sigma_{i}$, either according to Definition 1 (SCG) or Definition 2 (MCG), the strategy vector 
$\sigma=\left(\sigma_{1}, \ldots, \sigma_{\mathrm{N}}\right)$ is mapped into coalition structure $\mathrm{c}$, leading to valuation $\mathrm{v}=\left(\mathrm{v}_{1}, \ldots, \mathrm{v}_{\mathrm{N}}\right)$. Hence, we can define stable coalition structures in terms of $v_{i}(\psi(\sigma))$, but write only $v_{i}(\sigma)$ in the following if no misunderstanding is possible. More specifically, we can define stability in terms of equilibrium announcements $\sigma^{*}=\left(\sigma_{1}^{*}, \ldots, \sigma_{\mathrm{N}}^{*}\right)$ leading to coalition structure $\mathrm{c}^{*}$, and possible deviations $\sigma_{\mathrm{i}} \neq \sigma_{\mathrm{i}}^{*}$, leading to some coalition structure $\mathrm{c} \neq \mathrm{c}^{*}$, which should not pay in equilibrium.

There are many ways to define stability in the context of single and multiple coalitions, capturing the notions of open and exclusive membership. We chose definitions that are inspired by Carraro (1997 and 2000) which are closely related to the concept of internal\&external stability in order to stress similarities and differences. Moreover, we chose a compact definition to highlight differences in terms of membership rules. We start by defining stability in the single coalition game.

\section{Single Coalition Game}

Regardless which membership rule we consider, it is evident that no signatory should have an incentive to leave the agreement. This corresponds to the notion of internal stability. Moreover, an equilibrium coalition structure should also not be upset by a non-signatory joining the agreement. Under open membership, this requires that no non-signatory has an incentive to join the agreement. This is the classical definition of external stability that we call external stability condition 1 in Definition 4 below. Of course, if no non-signatory has an incentive to join the agreement, then an agreement is also stable under exclusive membership. In other words, there is no need to vote on accession since no outsider will submit an application for joining the agreement anyway. However, suppose a non-signatory has an incentive to join, then under exclusive membership the members of the agreement have to decide whether to accept a new member (external stability condition 2 in Definition 4 below). Due to the assumption of complete information, all members can evaluate whether they would benefit from the enlarged coalition. Under majority voting, accession will be accepted if a (strict) majority is in favor of the application (external stability condition 2.1) and under unanimity voting only if all members are in favor (external stability condition 2.2). In other words, a coalition structure that is not externally stable under open membership may be stable under exclusive membership if a (weak) majority (majority voting) or at least one member (unanimity voting) is against accession. More formally, we have: 


\section{Definition 4: Stability in the Single Coalition Game (SCG)}

In the single coalition game, denote the set of players that announce $\sigma_{i}^{*}=0$ by $I^{N C}$ with typical element $i$ and the set of players that announce $\sigma_{j}^{*}=1$ by $I^{C}$ with typical element $j$ $\left(I^{N C} \cap I^{C}=\varnothing\right)$. Let the set $I^{C}$ comprise $/ I^{C} /$ players and let $S$ be a subgroup of $/ \mathrm{S} /$ players in $I^{C}$. Then, coalition structure $c^{*}$, generated by announcements $\sigma^{*}$, is called stable

(i) under open membership if it satisfies conditions $a$ and b,

(ii) under exclusive membership majority voting if it satisfies condition a and either condition $b$ or $c .1$ and

(iii) under exclusive membership unanimity voting if it satisfies condition a and either b or c. 2 .

a) internal stability: $\forall i \in I^{C}: v_{i}\left(\sigma_{i}^{*}=1, \sigma_{-i}^{*}\right) \geq v_{i}\left(\sigma_{i}=0, \sigma_{-i}^{*}\right)$.

b) external stability 1: $\forall j \in I^{N C}: v_{j}\left(\sigma_{j}^{*}=0, \sigma_{-j}^{*}\right) \geq v_{j}\left(\sigma_{j}=1, \sigma_{-j}^{*}\right)$.

c) external stability 2: $v_{j}\left(\sigma_{j}^{*}=0, \sigma_{-j}^{*}\right)<v_{j}\left(\sigma_{j}=1, \sigma_{-j}^{*}\right)$,

and

c.1) $\exists S \subset I^{C}, / S / \geq \mid I^{C} / 2 /, \forall i \in S: v_{i}\left(\sigma_{j}^{*}=0, \sigma_{-j}^{*}\right)>v_{i}\left(\sigma_{j}=1, \sigma_{-j}^{*}\right)$.

c.2) $\exists i \in I^{C}: v_{i}\left(\sigma_{j}^{*}=0, \sigma_{-j}^{*}\right)>v_{i}\left(\sigma_{j}=1, \sigma_{-j}^{*}\right)$.

Notice that the last two conditions c. 1 and c.2 entail the effect on the payoff of player $i$ if player $\mathrm{j}$ changes his announcement strategy, intending to join coalition $\mathrm{I}^{\mathrm{C}}$. From Definition 4 it is evident that the "degree of exclusivity" rises from open to exclusive membership and is higher under unanimity than under majority voting. Hence, it is more difficult to upset an equilibrium coalition structure under exclusive membership than under open membership and under exclusive membership it is more difficult to upset an equilibrium under unanimity voting than under majority voting. Thus, if we abbreviate the set of equilibrium coalition structures in the single coalition game under open membership, exclusive membership and majority voting as well as exclusive membership and unanimity voting by $\mathrm{C}^{\mathrm{SCG}}(\mathrm{OM}), \mathrm{C}^{\mathrm{SCG}}(\mathrm{EM}-$ $\mathrm{MV})$ and $\mathrm{C}^{\mathrm{SCG}}(\mathrm{EM}-\mathrm{UV})$, then $\mathrm{C}^{\mathrm{SCG}}(\mathrm{OM}) \subset \mathrm{C}^{\mathrm{SCG}}(\mathrm{EM}-\mathrm{MV}) \subset \mathrm{C}^{\mathrm{SCG}}(\mathrm{EM}-\mathrm{UV})$ must hold by simple theoretical reasoning. Therefore, as pointed out in the introduction, the interesting question is: what are the welfare and ecological implications of these relations? We will answer this question in section 4 with the help of an empirical example. We turn now to stability in the context of the multiple coalition game. 


\section{Multiple Coalition Game}

In a multiple coalition structure, any member of a non-trivial coalition can leave its coalition to become a singleton by announcing an address that has not been announced before. Hence, internal stability is, again, a necessary condition for stability under all membership rules. Moreover, singletons can join a coalition by announcing the same address as coalition members of some coalition $c^{\mathrm{I}}$. However, singletons may also join another singleton. By the same token, members of a non-trivial coalition may join another non-trivial coalition or a singleton. Thus, in the context of multiple coalitions the meaning of external stability is less obvious than in the single coalition game. Hence, we introduce a term called intracoalitional stability. ${ }^{7}$ Under open membership, a coalition structure is intracoalitional stable if no player, regardless whether he/she is a singleton or belongs to a non-trivial coalition, has an incentive to join another coalition, regardless whether this is a trivial or non-trivial coalition (intracoalitional stability condition 1). However, in order to capture the notion of voluntary participation in an agreement, it seems necessary to make sure that if a player has an incentive to join a singleton player, this player has to agree to accession (intracoalitional stability condition 2). This ensures that singletons cannot be forced into cooperation and is captured by intracoalitional stability condition 2 in Definition 5 below. $^{8}$

Of course, if either no player has an incentive to change membership or if a player wants to join a singleton but this suggestion is turned down by the singleton, this coalition structure is also stable under exclusive membership. However, under exclusive membership, we also have to consider the possibility that a player, currently being a singleton or belonging to some nontrivial coalition, wants to join (or switch to) another non-trivial coalition, which may be turned down by majority voting (intracoalitional stability condition 3.1) or by unanimity (intracoalitional stability condition 3.2). More formally, we have:

\section{Definition 5: Stability in the Multiple Coalition Game (MCG)}

In the multiple coalition game, denote the set of players that belong to a non-trivial coalition by $I^{C}$ with typical element $i$, and $j$ where $i$ and $j$ are members of the same coalition $c^{I}$ because $\sigma_{i}^{*}=\sigma_{j}^{*}$; let coalition $c^{I}$ be of size $/ c^{I} /$ and denote a subset of players in $c^{I}$ by $c^{I(S)}$ with size $\mid c^{I(S)} /$; let the set of players that belong to trivial coalitions be denote by $I^{N C}$ with typical element $k$ and $l$ because $\sigma_{k}^{*} \neq \sigma_{m}^{*}$ and $\sigma_{l}^{*} \neq \sigma_{n}^{*}, m \in I \backslash\{k\}, n \in I \backslash\{l\}$ where $m$ and $n$ denote arbi-

7 Our definition comprises the notion of external and intercoalitional stability suggested by Carrarro (1997).

8 This is called restricted open membership in Rundshagen (2002). 
trary players that may belong either to $I^{C}$ or $I^{N C}$. Then, coalition structure $c^{*}$, generated by announcements $\sigma^{*}$, is called stable

(i) under open membership if it satisfies conditions a and either $b$ or $c$,

(ii) under exclusive membership and majority voting if it satisfies condition a and either $b, c$ or $d .1$ and

(iii) under exclusive membership and unanimity voting if it satisfies condition a and either $b, c$ or $d .2$.

a) internal stability: $\forall i \in I^{C}, \forall \sigma_{i} \neq \sigma_{m}^{*}, m \in I \backslash\{i\}: v_{i}\left(\sigma_{i}^{*}, \sigma_{-i}^{*}\right) \geq v_{i}\left(\sigma_{i}, \sigma_{-i}^{*}\right)$

b) intracoalitional stability 1: $\forall m \in I, \forall \sigma_{m}=\sigma_{n}^{*}, n \in I \backslash\{m\}: v_{m}\left(\sigma_{m}^{*}, \sigma_{-m}^{*}\right) \geq v_{m}\left(\sigma_{m}, \sigma_{-m}^{*}\right)$

c) intracoalitional stability 2: $\sigma_{m}=\sigma_{k}^{*}, k \in I \backslash\{m\}$, with $\sigma_{k}^{*} \neq \sigma_{l}^{*}, l \in I \backslash\{k\}$ :

$v_{m}\left(\sigma_{m}^{*}, \sigma_{-m}^{*}\right)<v_{m}\left(\sigma_{m}, \sigma_{-m}^{*}\right)$

and

$v_{k}\left(\sigma_{m}^{*}, \sigma_{-m}^{*}\right)>v_{k}\left(\sigma_{m}, \sigma_{-m}^{*}\right)$.

d) intracoalitional stability 3: $\sigma_{m}=\sigma_{i}^{*}=\sigma_{j}^{*}, m \notin c^{I}, i, j \in c^{I}: v_{m}\left(\sigma_{m}^{*}, \sigma_{-m}^{*}\right)<v_{m}\left(\sigma_{m}, \sigma_{-m}^{*}\right)$

and

d.1) $\exists c^{I(S)} \subset c^{I}, / c^{I(S)} \mid \geq / c^{I} / 2 /, \forall i \in c^{I(S)}: v_{i}\left(\sigma_{m}^{*}, \sigma_{-m}^{*}\right)>v_{i}\left(\sigma_{m}, \sigma_{-m}^{*}\right)$

d.2) $\exists i \in c^{I}: v_{i}\left(\sigma_{m}^{*}, \sigma_{-m}^{*}\right)>v_{i}\left(\sigma_{m}, \sigma_{-m}^{*}\right)$.

Following the same reasoning as in the single coalition game, it is straightforward to establish: $\mathrm{C}^{\mathrm{MCG}}(\mathrm{OM}) \subset \mathrm{C}^{\mathrm{MCG}}(\mathrm{EM}-\mathrm{MV}) \subset \mathrm{C}^{\mathrm{MCG}}(\mathrm{EM}-\mathrm{UV})$ where we may recall that MCG stands for multiple coalition game, OM, EM-MV and EM-UV denote open membership and exclusive membership under majority and unanimity voting, respectively, and $\mathrm{C}$ denotes the set of equilibria. As pointed out above, we expect that some equilibrium coalition structures comprise multiple non-trivial coalitions due to a higher flexibility of finding "suitable partners". However, it is also evident from the discussion that the amount of possible deviations in the multiple coalition context is substantially higher than in the single coalition context, making it easier to upset a potential equilibrium coalition structure. For instance, suppose that coalition structure $\mathrm{c}^{*}=(\{1,2\},\{3\},\{4\},\{5\},\{6\})$ is internally and externally stable under open membership in the single coalition game. Now suppose that player 3 has an incentive to join player 4 and vice versa. Then, $\mathrm{c}^{*}$ is not stable anymore in the multiple coalition game (and $\mathrm{c}^{*^{\prime}}=(\{1,2\},\{3,4\},\{5\},\{6\})$ may not be stable either). Thus, it will be interesting to observe in 
section 4, which of the two opposed effects is stronger and what this implies for the success of coalition formation.

\section{The Empirical Background of Coalition Formation}

\subsection{The CLIMNEG World Simulation Model}

The CLIMNEG World Simulation Model (henceforth abbreviated CWSM) is an integrated assessment, economy-climate model that resembles closely the seminal RICE model by Nordhaus and Yang (1996). We give here only a short and informal overview of CWSM, a more detailed description can be found in Eyckmans and Tulkens (1999). The key functions and parameters are provided in the Appendix.

CWSM incoporates an endogenous feedback of climate change damages on production and consumption possibilities. The economic part consists of a longterm dynamic, perfect foresight Ramsey type of optimal growth model with endogenous investment and carbon emission reduction decisions. The world is divided into six regions: USA, JPN (Japan), EU (European Union), CHN (China), FSU (Former Soviet Union) and ROW (Rest of the World). In each region and in every period $t$ the following budget equation describes how gross production, $\mathrm{Y}_{\mathrm{i}, \mathrm{t}}$, can be allocated to consumption, $\mathrm{Z}_{\mathrm{i}, \mathrm{t}}$, investment, $\mathrm{I}_{\mathrm{i}, \mathrm{t}}$, emission abatement costs, $\mathrm{Y}_{\mathrm{i}, \mathrm{t}} \mathrm{C}_{\mathrm{i}}\left(\mu_{\mathrm{i}, \mathrm{t}}\right)$, and climate change damage, $\mathrm{Y}_{\mathrm{i}, \mathrm{t}} \mathrm{D}\left(\Delta \mathrm{T}_{\mathrm{t}}\right)$ :

$$
Y_{i, t}=Z_{i, t}+I_{i, t}+Y_{i, t} C_{i}\left(\mu_{i, t}\right)+Y_{i, t} D_{i}\left(\Delta T_{t}\right)
$$

Gross production can be interpreted as "potential GDP", that is, what could be produced in the absence of the climate change problem. Abatement costs are an increasing and convex function of emission abatement $\mu_{\mathrm{i}, \mathrm{t}} \in[0,1]$. Abatement measures the relative emission reduction compared to the business-as-usual scenario (BAU) without any abatement policy. Climate change damages are an increasing and convex function of temperature change $\Delta T_{t}$. Abatement costs, $C_{i}\left(\mu_{i, t}\right)$, and climate change damages, $D_{i}\left(\Delta T_{i}\right)$, are treated as proportions of "potential production". Hence, total costs and damages are the product of costs and damages with "potential" production $\mathrm{Y}_{\mathrm{i}, \mathrm{t}}$, respectively.

Every region is characterized by a production function of the Cobb-Douglas type that maps combinations of capital stock and labour input into output. The capital stock increases with investment and decreases with some depreciation rate over time. Labour supply is assumed to be inelastic and hence production can be viewed as a function of endogenous capital input only. Technological progress is assumed to increase exogenously over time, shifting the production frontier outwards. Production gives rise to emissions of greenhouse gases that are 
linked through an emission-output ratio that decreases over time through technological progress. Emissions accumulate in the atmosphere according to a standard accumulation process. This takes in consideration that only a fraction of emissions adds to the stock of greenhouse gases and that the stock decays over time due to a natural process. Carbon concentration leads to an increase in temperature that causes environmental damages. We measure welfare of each country as aggregate lifetime discounted consumption:

$$
\mathrm{w}_{\mathrm{i}}(\mathrm{s})=\sum_{\mathrm{t}=0}^{\Omega} \frac{\mathrm{Z}_{\mathrm{i}, \mathrm{t}}}{\left[1+\rho_{\mathrm{i}}\right]^{\mathrm{t}}}
$$

where $\rho_{\mathrm{i}}$ stands for the discount rate of region $\mathrm{i}$ and $\Omega$ denotes the time horizon. The strategy vector s consists of a time path (35 decades, starting in 1990) for emission abatement and investment for all six regions, $\mathrm{s}=\left\{\mathrm{I}_{\mathrm{i}, \mathrm{t}}, \mu_{\mathrm{i}, \mathrm{t}}\right\}_{\mathrm{i} \in \mathrm{N} ; \mathrm{t}=0, \ldots, \Omega}$, and hence is of length $2 \times 35 \times 6=420$.

\subsection{Computing Valuations}

According to Definition 3, the valuation function maps coalition structures $\mathrm{c}=\left(\mathrm{c}^{1}, \ldots, \mathrm{c}^{\mathrm{M}}\right) \in \mathrm{C}$ into payoffs, $\mathrm{v}_{\mathrm{i}}(\mathrm{c})=\mathrm{w}_{\mathrm{i}}(\varepsilon(\mathrm{c}))=\mathrm{w}_{\mathrm{i}}\left(\mathrm{s}^{*}\right)$, via an instruction how players choose their economic strategies $\mathrm{s}$. Coalition $\mathrm{c}^{\mathrm{k}}$ chooses an investment and emission abatement strategy vector $\mathrm{s}^{\mathrm{k}}=\left\{\mathrm{I}_{\mathrm{i}, \mathrm{t}}, \mu_{\mathrm{i}, \mathrm{t}}\right\}_{\mathrm{i} \in \mathrm{c}^{\mathrm{k}} ; \mathrm{t}=0, \ldots, \Omega}$ in order to maximize the aggregate discounted welfare over all periods for given strategies $\mathrm{s}^{-\mathrm{k}}$ of other countries. This gives rise to two first order conditions of country $\mathrm{i}$ being a member of coalition $\mathrm{c}^{\mathrm{k}}$ in coalition structure $\mathrm{c}$ at time $\mathrm{t}$ (see Appendix for details). Given the public "bad" nature of emissions, the economic strategies of countries are interdependent. Therefore, we must simultaneously solve the two first order conditions for each country at each time $t$ for every coalition structure c. Since we assume complete information, the equilibrium strategy vectors can be interpreted as open loop Nash equilibria. In order to compute the valuation function numerically, we use a standard iterative algorithm. We never encountered convergence problems and found always a unique equilibrium for each of the 203 possible coalition structures.

As pointed out in section 2 , in the case of no transfers valuations $v_{i}(c)$ follow immediately from equilibrium economic strategies. In the case of transfers, we derive a "corrected valuation" $\hat{\mathrm{v}}_{\mathrm{i}}(\mathrm{c})=\mathrm{v}_{\mathrm{i}}(\mathrm{c})+\mathrm{t}_{\mathrm{i}}$. We adopt the transfer scheme used in Eyckmans and Tulkens (1999), which is a modification of the scheme proposed by Chander and Tulkens (1995 and 1997). The scheme assumes only transfers within coalitions where the surplus of a coalition $\mathrm{c}^{\mathrm{k}}$ from cooperation is allocated according to a proportional sharing rule:

$$
\mathrm{t}_{\mathrm{i}}=\left[\mathrm{v}_{\mathrm{i}}\left(\mathrm{c}^{\mathrm{N}}\right)-\mathrm{v}_{\mathrm{i}}(\mathrm{c})\right]+\lambda_{\mathrm{i}} \sum_{\mathrm{i} \in \mathrm{c}^{\mathrm{k}}}\left[\mathrm{v}_{\mathrm{i}}(\mathrm{c})-\mathrm{v}_{\mathrm{i}}\left(\mathrm{c}^{\mathrm{N}}\right)\right]
$$


where shares $\lambda_{i}$ are given by:

$$
\lambda_{\mathrm{i}}=\frac{\sum_{\mathrm{t}=0}^{\Omega} \frac{\mathrm{Y}_{\mathrm{i}, \mathrm{t}} \mathrm{D}_{\mathrm{i}}^{\prime}\left(\Delta \mathrm{T}_{\mathrm{t}}\right)}{\left[1+\rho_{\mathrm{i}}\right]^{\mathrm{t}}}}{\sum_{\mathrm{i} \in \mathrm{c}^{\mathrm{k}}} \sum_{\mathrm{t}=0}^{\Omega} \frac{\mathrm{Y}_{\mathrm{i}, \mathrm{t}} \mathrm{D}_{\mathrm{i}}^{\prime}\left(\Delta \mathrm{T}_{\mathrm{t}}\right)}{\left[1+\rho_{\mathrm{i}}\right]^{\mathrm{t}}}}
$$

and $v_{i}(c)$ denotes the valuation in some coalition $c$ and $v_{i}\left(c^{N}\right)$ the valuation in the singleton coalition structure. The first term in big brackets in (3) sets every country back to its welfare level in the singleton coalition structure, the second term allocates the total surplus of coalition $\mathrm{c}^{\mathrm{k}}$ compared to the singleton coalition structure in proportion to their marginal damages. Hence, the second term in (3) favors countries with relatively high potential production and/or marginal damage estimates and low discount rates since they are entitled to a larger share of their coalition's aggregate payoff. However, the first term ensures that members, which would lose from cooperation without transfers because they contribute much to joint abatement but benefit only little because of low marginal abatement and damage costs, break at least even provided there is a surplus from cooperation. That this may not generally be the case is evident by noting the following relations.

Suppose we start either from the singleton coalition structure $\mathrm{c}^{\mathrm{N}}$ or some other coalition structure $\mathrm{c}$ and that some countries or coalitions merge leading to coalition structure $\mathrm{c}^{\prime}$. This means a change of strategies not only of those countries involved in the merger (insiders) but also of those not involved (outsiders) and will affect welfare of all countries (valuations). Typically, insiders will increase their abatement efforts but this may be matched by an expansion of emissions of outsiders. The amount of these leakage effects depends on the particular coalition structure, on the parameters of the marginal damage and cost functions and on the physical parameters of the climate system. Thus, individual insiders may lose but also aggregate welfare of insiders may decline through a merger. However for our data set, it turns out that a merger always increases aggregate welfare of insiders. That is, the superadditivity property holds. ${ }^{9}$ Hence, our transfer scheme ensures that each coalition member receives in any coalition structure different from the singleton coalition structure a higher valuation. However, this does not imply that individual insiders are better off in a coalition structure $c^{\prime} \neq \mathrm{c}^{\mathrm{N}}$ compared to a coalition structure $\mathrm{c} \neq \mathrm{c}^{\mathrm{N}}$ where $\mathrm{c}^{\prime}$ is derived from a merger of insiders. In fact, it is a fundamental feature of coalition formation in the context of a

\footnotetext{
9 A formal definition is provided for instance in Bloch (1997).
} 
global environmental problem that this property does not hold, otherwise full cooperation would always be an equilibrium outcome.

In addition, in our global warming game it can be empirically established that outsiders always benefit from a merger, irrespective whether we assume transfers or not. That is, in our game, the positive externality property holds (see previous footnote) - a feature that illustrates the free-rider incentive in global pollution control. This has two implications. Firstly, every country is better off in any coalition structure different from the singleton coalition structure with transfers. Without transfers, this is only generally true for singletons. Secondly, we do not have to consider profitability as a separate condition in our definition of stability (see, e.g., Carraro and Siniscalco 1993) because it is straightforward to show that internal stability is a sufficient condition for profitability (see Finus and Rundshagen 2003a).

\subsection{Reference Simulations}

In order to highlight some general features of our empirical model, we consider some benchmark simulation.

\section{Carbon Emissions and Concentration}

Figure 1 shows annual world carbon emissions in three scenarios: business-as-usual (BAU), implying no emission reduction ( $\mu_{\mathrm{i}, \mathrm{t}}=0 \forall \mathrm{i}, \forall \mathrm{t}$ ), Nash equilibrium (NASH), corresponding to the singleton coalition structure, and social optimum, SOCIAL, correponding to the grand coalition. ${ }^{10}$ We only consider carbon emissions originating from fossil fuel use where world carbon emissions in 1990 amount to approximately 6 gigatons of carbon. BAU-emissions continuously grow, reach nearly $40 \mathrm{GtC}$ by the year 2100 , and more than $62 \mathrm{GtC}$ in 2200 . NASH-emissions grow at a slightly slower rate. In contrast, SOCIAL-emissions are substantially lower: in 2100 they amount to roughly $24 \mathrm{GtC}$, and only $21 \mathrm{GtC}$ in 2200 . This is about half of NASH-emissions in 2100 and almost one third of NASH-emissions in 2200. In contrast to NASH and BAU-emissions, the SOCIAL-emission path rises only until 2150 , levels off at about $26 \mathrm{GtC}$, and decreases afterwards.

\section{FIGURE 1 and FIGURE 2 about here}

Figure 2 shows the atmospheric carbon concentration. In 1990 atmospheric carbon concentration amounts to approximately $750 \mathrm{GtC}$. BAU-concentration rises steadily and reaches about $1718 \mathrm{GtC}$ in 2100 and $3443 \mathrm{GtC}$ in 2200 . Doubling of the concentration with

\footnotetext{
10 All figures report data for a time horizon of 1990 to 2250 . However, all calculations were conducted for the entire time period of 350 years.
} 
respect to 1990 takes place between 2080 and 2090. The NASH-concentration path follows closely the BAU-path. In contrast, SOCIAL-concentration grows at a much slower rate and reaches $1368 \mathrm{GtC}$ in 2100 and $2017 \mathrm{GtC}$ in 2200. Doubling of atmospheric carbon concentration is postponed until some time between 2110 and 2120 . The carbon concentration levels off at about $2000 \mathrm{GtC}$ by the year 2200 .

At the level of individual countries there are substantial differences across regions. Taking averages of abatement over time, we find in the Nash equilibrium that $C H N$ abates about $7.70 \%$, followed by $E U$ with $7.24 \%$ and $U S A$ with $6.44 \%$. The lowest abatement effort is undertaken by $R O W$ with only $1.45 \%$. World average abatement amounts to $3.74 \%$. For $R O W$ low abatement is due to strong free-rider incentives within this heterogeneous region. ${ }^{11}$ For $C H N$ high abatement is due to low marginal abatement costs and for $E U$ this is due to their high climate change damage valuation. In the social optimum world average abatement is $37.14 \%$. $C H N$ and $R O W$ are required to reduce their emissions substantially more than other regions (68.13\% and $55.50 \%$, respectively) due to their low marginal abatement costs.

\section{Macroreconomic Magnitudes}

Figures 3 and 4 show the time profiles of world consumption, Z, investment, I, abatement cost, YC, and damage costs, YD, for NASH- and SOCIAL-scenario where potential production, $\mathrm{Y}$, is the sum of these components (see (1)). It is evident that production and consumption profiles are quite similar in both scenarios. Small differences stem from the fact that abatement costs and damage costs constitute a small portion of total production and consumption. Hence, strong differences in the emission and concentration path in both scenarios do not alter YC+YD. However, the composition of YC and YD is different in the two scenarios. In the Nash equilibrium abatement costs are very small (they do not show up in Figure 3) but climate change damage are high. In contrast, in the social optimum damages are relatively small but this gain requires devoting part of the production to emission abatement.

\section{FIGURE 3 and FIGURE 4 about here}

Table 1 displays total discounted consumption $\mathrm{v}_{\mathrm{i}}(\mathrm{c})=\mathrm{w}_{\mathrm{i}}\left(\mathrm{s}^{*}\right)=\sum_{\mathrm{t}=0}^{\Omega} \mathrm{Z}_{\mathrm{i}, \mathrm{t}} /\left[1+\rho_{\mathrm{i}}\right]^{\mathrm{t}}$ for each region in the Nash equilibrium, $\mathrm{v}_{\mathrm{i}}^{\mathrm{N}}$, and in the social optimum, $\mathrm{v}_{\mathrm{i}}^{\mathrm{S}}$. The last row World reveals the overall magnitudes at stake. Though the gain at the world level from full cooperation is not a small number $(1,771$ million $\$)$, in relative terms it amounts to only

11 As in Nordhaus and Yang (1996), we have revised downward the climate change damage parameter of $R O W$ in all partitions in which $R O W$ is a singleton in order to account for the fact that this region consists of many countries. 
$0.52 \%$. This is due three reasons. Firstly, as pointed out above, abatement costs and climate change damages are small compared to production or consumption. Secondly, differences between both scenarios in terms of welfare occure mainly in the far future but receive less weight due to discounting. Thirdly, abatement costs are relatively high compared to the benefits from reduced emissions, so that also in the social optimum only moderate action is required. Nevertheless, there are large differences between both scenarios in ecological terms: emissions are 106 and concentration is 138 percent higher in the Nash equilibrium than in the social optimum (see also Table 2 and 3 in section 4).

Table 1: World Discounted Consumption*

\begin{tabular}{ccccccc}
\hline & $\mathrm{v}_{\mathrm{i}}^{\mathrm{N}}$ & $\mathrm{v}_{\mathrm{i}}^{\mathrm{S}}$ & $\left(\mathrm{v}_{\mathrm{i}}^{\mathrm{S}}-\mathrm{v}_{\mathrm{i}}^{\mathrm{N}}\right) / \mathrm{v}_{\mathrm{i}}^{\mathrm{S}}$ & $\mathrm{t}_{\mathrm{i}}$ & $\hat{\mathrm{v}}_{\mathrm{i}}^{\mathrm{S}}$ & $\left(\hat{\mathrm{v}}_{\mathrm{i}}^{\mathrm{S}}-\mathrm{v}_{\mathrm{i}}^{\mathrm{N}}\right) / \hat{\mathrm{v}}_{\mathrm{i}}^{\mathrm{S}}$ \\
\hline USA & 78,352 & 78,989 & +0.81 & -286 & 78,703 & +0.45 \\
JPN & 42,909 & 43,224 & +0.73 & -123 & 43,101 & +0.45 \\
EU & 102,730 & 103,654 & +0.89 & -429 & 103,225 & +0.48 \\
CHN & 9,140 & 8,856 & -3.21 & +338 & 9,194 & +0.59 \\
FSU & 23,794 & 24,025 & +0.96 & -124 & 23,901 & +0.45 \\
ROW & 81,135 & 81,083 & -0.06 & +624 & 81,707 & +0.70 \\
\hline WORLD & $\mathbf{3 3 8 , 0 6 0}$ & $\mathbf{3 3 9 , 8 3 1}$ & $\mathbf{+ 0 . 5 2}$ & $\mathbf{0}$ & $\mathbf{3 3 9 , 8 3 1}$ & $+\mathbf{0 . 5 2}$ \\
\hline
\end{tabular}

* Figures are the discounted sum of consumption in million US\$ $\$_{1990}$. All variables as explained in the text.

In terms of individual winners and losers, we find that $C H N$ and, to a lesser extent, $R O W$ would lose from full cooperation without transfers. ${ }^{12}$ With transfers, however, profitability holds for all countries in the social optimum and as mentioned above for any other coalition structure different from the grand coalitions as well. Hence, without transfers the grand coalition can never be an equilibrium. However, profitability is only a necessary condition for stability and, as we will see from section 4 , by no means sufficient to guarantee stability.

\section{Stable Coalition Structures}

In this section, we report on results of our stability analysis. In subsection 4.1, we explain the information contained in Table 2 and 3 and in subsection 4.2 we provide some rationale that helps to explain membership in stable coalitions. In subsection 4.3, we evaluate stable coalition structures.

\footnotetext{
12 A more detailed analysis of the incentive to cooperate is provided in subsection 4.2.
} 


\subsection{Information in Table 2 and 3}

Table 2 and 3 list stable coalition structures in the no transfer and transfer case, respectively. The first column lists the number of a particular coalition structure where to each coalition structure a number between 1 and 203 is attached. Coalition structure no. 1 represents the singleton coalition structure, corresponding to the "conventional" Nash equilibrium, whereas coalition structure no. 203 is the grand coalition, corresponding to the "conventional" social optimum. Moreover, coalition structure no. 196 represents the "old Kyoto coalition" before the US decided to withdraw from the Kyoto Protocol and coalition structure no. 87 corresponds to the "new Kyoto coalition" after the US-withdrawal. Apart from stable coalition structures, these coalition structures are listed because they represent interesting benchmarks.

Column 2 lists coalition structures in partition form where non-trivial coalitions are indicated bold. Column 3, 4 and 5 contain information whether a coalition is stable ( $\mathrm{n}=$ not stable, $\mathrm{y}=$ stable and $-=$ not defined) in the single (S) and multiple coalition game (M) under open membership (OM) and under exclusive membership majority voting (EM-MV) and unanimity voting (EM-UV).

\section{TABLE 2 and 3 about here}

Column 6 gives total discounted welfare over all regions and the entire (1990-2330). We take this feature to sort coalition structures in descending order. Column 8 gives concentration at the end of the period and column 10 indicates global cumulative emissions over the entire period. In order to evaluate coalition structures, we compute a "degree of externality index" (DEX). This index measures the differences between the outcome in some coalition structure c and the social optimum (grand coalition) in relation to the social optimum, expressed as percentage. By definition, in the social optimum the degree of externality is 0 . Columns 7, 9 and 11 display this index for welfare, concentration and emissions, respectively. All numbers have been rounded to "sensible" digits.

\subsection{Membership in Stable Coalition Structures}

From a first glance at Tables 2 and 3, it seems that intuition is not confirmed: in many coalitions there are members of which one would expect that they should show little interest in forming a coalition and/or not with those regions listed in Table 2 and 3. For instance, in the context of no transfers, it may be suspected that the "rest of the world" (ROW) should show little interest in participating in an agreement and that USA and ROW will hardly be in one coalition because of different interests. However, a closer inspection of the underlying fundamentals resolves this puzzle. 
Firstly, climate change damage parameters in our model are modified estimates of RICE that may not be in line with the presumed perception of regions' damages. For instance, it has been argued that developing countries will pay little attention to environmental damages due to strong preferences for economic growth. This would suggest for instance that the damage costs of ROW should be very low, though in our model they are relatively high, despite we assume higher discount rates for ROW and CHN than for the rest of the countries (see Appendix).

Secondly, the conjecture that countries forming a coalition with other countries are the "good guys" and countries remaining singletons are the "bad guys" is premature. This conjecture presumes that coalition members will substantially reduce their emissions compared to the non-cooperative benchmark and compared to outsiders. However, this may not always be the case. For instance, suppose two regions that both have high marginal abatement costs and low marginal damages costs form a coalition. Then joint welfare maximization calls only for a moderate emission reduction. Hence, internal stability will not be much of a problem for these regions. In contrast, a singleton with low marginal abatement costs and high marginal damage costs may already reduce emissions substantially by itself.

Thirdly, not only low abatement but also a homogenous incentive structure among coalition members is important for internal stability. In the case of no transfer, clearly, homogenous incentives follow from similar marginal abatement and damage costs patterns. However, also a region of type 1 (e.g., ROW) with relatively low marginal abatement costs and high marginal damages and a region of type 2 (e.g., JPN) where this is reversed have a similar incentive structure. Type 1 contributes much to joint abatement but also benefits much whereas for type 2 this is reversed. Hence, contributions and gains are equally distributed. In such a coalition also a region of type 3 (e.g., USA and FSU) with moderate marginal abatement costs and marginal damages may fit in. This explains why USA, JPN, FSU and ROW are frequent members of stable coalition structures as listed in Table 2.

In contrast, a region of type 4 (e.g., EU) with relatively high marginal abatement and damage costs finds it difficult to find partners for cooperation (though it has much interest in cooperation). It contributes relatively little to joint abatement but benefits more than proportionally. Moreover, it causes that a high abatement target is implemented within the coalition due to its high marginal damages. This explains why EU is a member of a coalition in only two coalition structures listed in Table 2.

Finally, a region of type 5 (e.g., CHN) with low marginal abatement and marginal damage costs would find many cooperating partners but has no incentive itself to join a coalition as 
long as there is no compensation. This explains why $\mathrm{CHN}$ is no coalition member of any stable coalition structure listed in Table 2. This is different in the case of transfers (see Table 3). Now interests are more balanced. $\mathrm{CHN}$ is compensated for her high contribution and receives a fair share of the gains from cooperation. For other regions, cooperation with $\mathrm{CHN}$ but also with ROW is attractive since this lowers abatement costs of joint cooperation.

Fourthly, not only the lack of internal stability but also of external or intracoalitional stability explains membership. For instance, under open membership and to some extent under exclusive membership with majority voting coalitions including $\mathrm{CHN}$ are not stable because outsiders would have an incentive to join.

\subsection{Evaluating Stable Coalition Structures}

\section{General comments}

From Tables 2 and 3, it is evident that the singleton coalition structure (no. 1) is stable in the single but not in the multiple coalition game. In the single coalition game this is an "artificial result" of the construction of the game but does not affect the subsequent interpretations. If each player announces $\sigma_{i}=0$, then no single player can change his/her membership by a single deviation. In other words, the singleton coalition structure is stable by definition. ${ }^{13}$ In the multiple coalition game, this is different. Suppose each player announces a different address. Then coalition structure no. 1 is only stable if either no player has an incentive to join another singleton by announcing the same address (intracoalitional stability 1) or if there is such an incentive and the second player has no interest in such a merger (intracoalitional stability 2). However, since there are four coalition structures of the form $(\{i, j\},\{k\},\{1\},\{m\},\{n\})$ in the no transfer case (no. 2, 4, 5 and 6) and five in the transfer case (no. 2, 3, 4, 5 and 6) that are internally stable, it is evident that there are enough regions that have an interest in a merger with another region and hence no. 1 cannot be intracoalitional stable.

The grand coalition is not stable regardless how stability is defined. In the no transfer case this follows immediately from the fact that $\mathrm{CHN}$ and ROW are worse off than in the singleton coalition structure (see Table 1). However, profitability is only a necessary but not a sufficient condition for internal stability. An important reason for instability is high abatement contributions of all participants as this is the case in the social optimum. Hence, it is particular attractive for a member to leave the grand coalition because this reduces abatement costs substan-

13 Of course, the advantage of this construction is that existence of an equilibrium is guaranteed which may not be the case in the multiple coalition game. For discussion of this and related issues see Finus/Rundshagen (2003c). 
tially but increases damages only moderately. A similar argument explains why also coalitions of five or four regions are not stable: the incentive to leave a coalition increases with the number of coalition members. Therefore, it also not surprising that we find in line with other studies (e.g., Barrett 1998, Bosello et al. 2001, Eyckmans 2001, Finus et al. 2003 and Tulkens et al. 1999) that neither the "old" nor the "new" Kyoto coalition is stable. Of course, in our setting abatement targets follow from the assumption of the valuation function and may therefore differ from those agreed in Kyoto and subsequent COP-meetings. Also welfare implications may be different because we do not model permit trading. Nevertheless, our results help to explain the difficulties in Kyoto and subsequent meetings to reach a final agreement and to gather enough ratification so that the protocol enters into force.

Interestingly, our results also suggest that both Kyoto coalitions (new and old) would not much narrow the gap between social optimum and Nash equilibrium and that there are many other coalition structures that would perform far better. Given the caveats mentioned above, this indicates that a subgroup of the Kyoto coalition could improve upon the outcome of the negotiations by looking for different members. Of course, this may require some transfer to provide sufficient incentives for others to join.

Our results also confirm two general conclusions from the theoretical literature assuming symmetric countries that have been mentioned in the introduction. 1) The number of participants is not necessarily a good indicator for the success of an IEA. For instance, the old Kyoto coalition (coalition structure no. 196) counts four members, is not stable, and is inferior in welfare and ecological terms to many other stable coalition structures with and without transfers. Also coalition structure no. 4 with only one coalition of two members is superior to coalition structure no. 20 with one coalition of three members and no. 153 with two coalitions of two members that are all stable in the multiple coalition game under exclusive membership, unanimity voting and no transfers (see Table 2). 2) Whenever the degree of externality is low, only small coalitions are stable but they achieve much and if the degree is high, the opposite holds. In our context, this degree is small in welfare terms ( 0.52 percent; though admittedly it is larger in ecological terms) since abatement costs are relatively high compared to the benefits from reduced damages. In our setting, the largest single coalition comprises three members and the largest coalition in a coalition structure with multiple coalitions comprises two members. Nevertheless, those small coalitions close the gap between social optimum and Nash equilibrium substantially. For instance, in the case of no transfer coalition structure no. 26 (that is stable under EM-UV; see Table 2) reduces the gap by more than a half in welfare and ecological terms and in the case of transfers coalition structure no. 31 (that is stable under EM-MV and EM-UV in the multiple coalition game; see Table 3) closes this gap even 
more. As Barrett (1994) pointed out, this relation may be reversed for CFCs, predicting large coalitions but less success for solving the problem of the depletion of the ozone layer effectively.

\section{Open versus exclusive membership}

In the no transfer case (Table 2), it is evident that no non-trivial coalition structure is stable under open membership, a few are stable under exclusive membership and majority voting and relatively many under exclusive membership and unanimity voting. This applies to the single and multiple coalition game. More important, those additional equilibrium coalition structures imply higher welfare and lower emissions and concentrations. In the case of transfers, the difference is less pronounced. In the single coalition game, the set of equilibrium coalitions for all membership rules is the same. However, in the multiple coalition game, a similar general conclusion as mentioned for no transfers can be drawn.

From a theoretical point of view, the results are interesting since they suggest that the assumption of open membership is crucial for the negative conclusions derived in the literature. From an applied point of view, the results are interesting in two respects. Firstly, it suggests that it may be worthwhile to think whether to adopt an exclusive membership rule, which is typical for club good agreements, also for public good agreements like those on climate change in the future. Majority voting is inferior to unanimity voting but still improves on the open membership rule. Secondly, voting under exclusive membership requires some degree of consensus among coalition partners. Thus, though it is usually argued that the need for consensus within international organization and governments has a negative impact on efficiency and effectiveness, in the present context consensus is conducive to cooperation, helping to stabilize an IEA.

\section{Single versus Multiple Coalitions}

Firstly, we observe that if coalition formation is not restricted to a single coalition multiple coalitions emerge in equilibrium. Of course, considering the membership in these coalition structures suggest that it is more appropriate to talk about multiple instead of regional agreements. It is not the geographical distance that decides on membership but the "distance in the incentive pattern". Secondly, we observe that in the case of transfers the four firstly ranked coalition structures in terms of global welfare are coalition structures with multiple coalitions. Thirdly, our previous conjecture of section 2 is confirmed that regions that have no incentive to join a coalition will form their own coalition if this is possible and this implies a Paretoimprovement. For instance, in the case of no transfers coalition structure no. 2 $(\{\mathrm{FSU}, \mathrm{ROW}\},\{\mathrm{USA}\},\{\mathrm{JPN}\},\{\mathrm{EU}\},\{\mathrm{CHN}\})$ is stable in the single coalition game under 
exclusive membership. In the multiple coalition game, this coalition structure is not stable anymore because USA and JPN have an incentive to form a second coalition leading to coalition structure no. 153 ( $\{\mathrm{USA}, \mathrm{JPN}\},\{\mathrm{FSU}, \mathrm{ROW}\},\{\mathrm{EU}\},\{\mathrm{CHN}\})$. Because of the positive externality property, this implies that not only USA and JPN benefit from this merger but all other regions as well. A similar relation holds for coalition structures like no. 4 and 155 and in the case of transfers between coalition structures no. 5 and 30, no. 6 and 31, no. 3 and 117 and no. 4 and 46. This suggests that lifting the restriction of a single agreement has a positive impact on cooperation. Obviously, in our setting, the higher flexibility of finding suitable cooperators outweighs the higher flexibility in terms of possible deviations in a multiple coalition game compared to a single coalition game.

From a theoretical point of view the results are interesting in two respects. Firstly, they demonstrate that not only for symmetric players but also for heterogeneous players we can expect that multiple coalitions form in equilibrium. Secondly, they illustrate that the option to form multiple coalitions will enhance the prospectives for cooperation - a conjecture that could not be substantiated by theory so far. From an applied point of view our results support the efforts in recent IEAs not to treat all members and potential members equally. In fact, it may be worthwhile to draft different protocols that suite different groups of countries. In this sense, it may be questioned whether it was a clever strategy by the USA before they dropped out of the Kyoto Protocol to link their ratification to the acceptance of emission ceilings by developing countries like $\mathrm{CHN}$ and India. It may well be the case that more could have been achieved if separate protocols were designed for industrialized countries, developing countries and countries in transition.

\section{No transfers versus transfers}

Tables 2 and 3 reveal that the first four stable coalition structures in the multiple coalition game under exclusive membership in the case of transfers (no. 31 to 30 ) are superior to the coalition structure with the highest welfare in the case of no transfers (no. 26). Thus, the conjecture is confirmed that transfers are an important tool to increase participation and the success of stable agreements. Nevertheless, also transfers cannot totally overcome free-rider incentives and hence stable coalition structures comprise only small coalitions and welfare is below, as well as concentration and emissions are above globally optimal levels.

The results are in line with almost all theoretical and empirical findings of coalition models that show that transfers lead to superior outcomes (see the literature discussed and cited in Finus 2003a). The results also support efforts within recent IEAs, like the Montreal and Kyoto Protocol, to establish multilateral funds that compensate developing countries for cooperation. 


\section{Summary and Conclusions}

We modeled coalition formation in international climate change control as a two stage game: in the first stage countries/regions decide on their membership in a coalition and in the second stage coalition members choose their economic strategies. For the first stage, we considered a single and a multiple coalition game. In the second stage, we assumed that coalition members jointly choose abatement and capital investment strategies as to maximize the aggregate welfare to their coalition. We argued that the entire game can be analyzed as a reduced stage game in which players decide on their membership since they know the welfare implications of the second stage. Consequently, stability can be defined in terms of membership strategies. We considered two modifications of the classical definition of internal and external stability that implicitly makes two assumptions: a) open membership (no restriction on accession to an agreement) and b) single agreement (regions can only decide to sign or not to sign an agreement but cannot form separate agreements). The first modification extended open membership to exclusive membership. That is, players that have an incentive to join a coalition require the consent of the existing members. We modeled this as a voting procedure where members either decide by majority or unanimity voting on the application of accession. The second modification lifted the restriction of a single agreement and allowed for the co-existence of multiple agreements.

We used an empirical growth equilibrium model that captures a time horizon of 350 years to compute payoff vectors (valuations) for six world regions and for each of the 203 possible coalition structures. Subsequently, we computed stable (equilibrium) coalition structures and evaluated them in terms of global welfare, concentration and total emissions. From the many results, we would like to mention four. 1) Neither the grand coalition, which is identical to the social optimum, nor the Kyoto coalition in its original (including USA) and in its present form (without the USA) are stable, regardless of the membership rule. Only coalitions with few members are stable. Nevertheless, in the context of climate change they can close the gap between no and full cooperation to a large extent. Thus, "small may be beautiful (or least not that ugly)"! 2) Under exclusive membership more coalition structures are stable than under open membership that are also superior in welfare and ecological terms. This is particularly true for unanimity voting. We suggested considering changing the open access rule of most IEAs to restricted access in future IEAs as implied by most club good agreements. Moreover, the results indicate that the need for consensus in international politics may not always hamper, but, in fact, may be conducive for the implementation of ambitious abatement policies. 3) Many stable coalition structures comprise multiple coalitions that are superior to a 
single coalition in welfare and ecological terms. The reason is that it is difficult to form one large coalition because of strong free-rider incentives but it is easier to form several small coalitions because interests within a coalition are more homogeneous. This suggests not pursuing a strategy to get as many countries into "one climate boat" in future treaties but to allow for different protocols/agreements. 4) Without transfers, countries with a similar incentive structure in terms of marginal abatement and damage costs form coalitions. Countries with simultaneously either very low or high marginal abatement and damage costs will usually not participate in cooperation since they do not find "equally-minded" partners. With transfers, contrasting interests can be balanced. This allows reaping efficiency gains from cooperation. The result supports the efforts in recent IEAs like the Kyoto and Montreal Protocol to raise participation of developing countries via compensation payments.

For future research, we would like to mention three (of certainly many possible) extensions. Firstly, other transfer schemes than the Chander/Tulkens' transfer rule that we considered could be analyzed. The purpose of this exercise would be to find an "optimal transfer scheme" that allows - in the face of heterogeneous interests - for stable coalition structures generating high global welfare. Secondly, and closely related to the first point, the effect of different permit trading schemes on coalition formation could be analyzed. This may include the currently discussed schemes in the Kyoto Protocol but also alternative forms as discussed for instance in Böhringer (2002), Buchner and Carraro (2003), Kverndokk (1995) and Rose et al. (1998). Thirdly, stability may not only be defined in terms of single deviations but also in terms of multiple deviations. Whereas this is a straightforward exercise in theory (e.g., Finus and Rundshagen 2003c), we recognize that this is an ambitious task in an empirical context of 203 different coalition structures.

\section{References}

Barrett, S. (1994), Self-Enforcing International Environmental Agreements. "Oxford Economic Papers", vol. 46, pp. 804-878.

Barrett, S. (1997), Heterogeneous International Agreements. In: C. Carraro (ed.), International Environmental Negotiations: Strategic Policy Issues. Edward Elgar, Cheltenham, pp. 9-25.

Barrett, S. (1998), Political Economy of the Kyoto Protocol. "Oxford Review of Economic Policy", vol. 14, pp. 20-40.

Bloch, F. (1997), Non-Cooperative Models of Coalition Formation in Games with Spillovers. In: Carraro, C. and D. Siniscalco (eds.), New Directions in the Economic Theory of the Environment. Cambridge University Press, Cambridge, ch. 10, pp. 311-352.

Böhringer, C. (2002), Climate Politics from Kyoto to Bonn: From Little to Nothing?, "The Energy Journal", vol. 23, pp. 51-71. 
Bosello, F., Buchner, B., Carraro, C. and D. Raggi. (2001), Can Equity Enhance Efficiency? Some Lessons from Climate Negotiations. FEEM-Working Paper No. 49.2001, forthcoming in C. Carraro and V. Fragnelli (eds.), Game Practice and the Environment, Edward Elgar, Cheltenham, UK.

Botteon, M. and C. Carraro (1997), Burden-Sharing and Coalition Stability in Environmental Negotiations with Asymmetric Countries. In: Carraro, C. (ed.), International Environmental Negotiations: Strategic Policy Issues. Edward Elgar, Cheltenham et al., ch. 3, pp. 26-55.

Buchner, B. and C. Carraro (2003), Emission Trading Regimes and Incentives to Participate in International Climate Agreements. CATEP Policy Brief No. 3, 2003.

Buchner, B., C. Carraro, I. Cersosimo and C. Marchiori. (2002), Back to Kyoto? US Participation and the Linkage between R\&D and Climate Cooperation. CEPR Discussion Paper 3299.

Carraro, C. (1997), The Structure of International Environmental Agreements. Working Paper, Fondazione Eni Enrico Mattei. Revised version appeared as: The Structure of International Agreements on Climate Change, in: Carraro C. (ed.), International Environmental Agreements on Climate Change, Kluwer Academic Publishers, Dordrecht, 1999.

Carraro, C. (2000), Roads towards International Environmental Agreements. Siebert, H. (ed.), The Economics of International Environmental Problems, Mohr Siebeck, Tübingen, pp. 169-202.

Carraro C. and C. Marchiori (2003), Stable Coalitions. Forthcoming in Carraro, C. (ed.), Endogenous Formation of Economic Coalitions, Edward Elgar, Cheltenham, UK.

Carraro, C. and D. Siniscalco (1993), Strategies for the International Protection of the Environment. "Journal of Public Economics", vol. 52, pp. 309-328.

Chander, P. and H. Tulkens (1995), A Core-Theoretic Solution for the Design of Cooperative Agreements on Transfrontier Pollution. "International Tax and Public Finance", vol. 2, pp. 279-293.

Chander, P. and H. Tulkens (1997), The Core of an Economy with Multilateral Environmental Externalities. "International Journal of Game Theory", vol. 26, pp. 379-401.

Cornes, R. and T. Sandler (1996), The Theory of Externalities, Public Goods and Club Goods. $2^{\text {nd }}$ edition. Cambridge: Cambridge University Press.

Endres, A. (1997), Negotiating a Climate Convention - The Role of Prices and Quantities. "International Review of Law and Economics", vol. 17, pp. 201-224.

Eyckmans, J. (1999), Strategy Proof Uniform Effort Sharing Schemes for Transfrontier Pollution Problems. "Environmental and Resource Economics", vol. 14, pp. 165-189.

Eyckmans, J. (2001), On the Farsighted Stability of the Kyoto Protocol. Working Paper Series, Faculty of Economics and Applied Economic Sciences, University of Leuven, No. 2001-03.

Eyckmans, J., S. Proost, and E. Schokkaert (1993), Equity and Efficiency in Greenhouse Negotiations. "Kyklos", vol. 46, pp. 363-397. 
Eyckmans, J. and H. Tulkens (1999), Simulating with RICE Coalitionally Stable Burden Sharing Agreements for the Climate Change Problem. CES ifo Working Papers Series, No. 228, Munich, forthcoming in Resource and Energy Economics.

Finus, M. (2001), Game Theory and International Environmental Cooperation. Edward Elgar, Cheltenham.

Finus, M. (2003a), Stability and Design of International Environmental Agreements: The Case of Transboundary Pollution. In: Folmer, H. and T. Tietenberg (eds.), International Yearbook of Environmental and Resource Economics, 2003/4, Edward Elgar, Cheltenham, UK, ch. 3, pp. 82-158.

Finus, M. (2003b), New Developments in Coalition Theory: An Application to the Case of Global Pollution. In: Marsiliani, L., Rauscher, M. and Withagen, C. (eds.), Environmental Policy in an International Perspective, Kluwer, Dordrecht, Holland, pp. 19-49.

Finus, M., E. van Ierland and R. Dellink (2003), Stability of Climate Coalitions in a Cartel Formation Game. Working Paper No. 343, University of Hagen.

Finus, M. and B. Rundshagen (1998), Toward a Positive Theory of Coalition Formation and Endogenous Instrumental Choice in Global Pollution Control. "Public Choice", vol. 96, pp. 145-186.

Finus, M. and B. Rundshagen (2003a), Endogenous Coalition Formation in Global Pollution Control. Forthcoming in Carraro, C. (ed.), Endogenous Formation of Economic Coalitions, Edward Elgar, Cheltenham, UK.

Finus, M. and B. Rundshagen (2003b), A Non-Cooperative Foundation of Core-Stability in Positive Externality NTU-Coalition Games. Working Paper 31.2003, Fondazione Eni Enrico Mattei, 2003.

Finus, M. and B. Rundshagen (2003c), How the Rules of Coalition Formation Affect Stability of International Environmental Agreements. Preliminary Draft, University of Hagen.

Funaki, Y. and T. Yamato (1999), The Core of an Economy with a Common Pool Resource: a Partition Function Form Approach. "International Journal of Game Theory", vol. 28, pp. 157-171.

Guttman, J.M. (1998), Unanimity and Majority Rule: the Calculus of Consent Reconsidered. "European Journal of Political Economy", vol. 14, pp. 189-207.

Hoel, M. (1992), International Environment Conventions: The Case of Uniform Reductions of Emissions. "Environmental and Resource Economics", vol. 2, pp. 141-159.

IPCC (2001), Climate Change 2001: Mitigation. Contribution of Working Group III to the Third Assessment Report of the Intergovernmental Panel on Climate Change, Cambridge: Cambridge University Press.

Kverndokk, S. (1995), Tradeable $\mathrm{CO}_{2}$ Emission Permits: Initial Distribution as a Justice Problem. "Environmental Values", vol. 4, pp. 129-148.

Mueller, D. (2003), Public Choice III. Cambridge: Cambridge University Press.

Nordhaus, W.D. (1993), Rolling the "DICE": An Optimal Transition Path for Controlling Greenhouse Gases. "Resource and Energy Economics", vol. 15, pp. 27-50. 
Nordhaus, W.D. and Z. Yang (1996), A Regional Dynamic General-equilibrium Model of Alternative Climate-change Strategies. "American Economic Review", vol. 86, pp. 741-765.

Rose, A., B. Stevens, J. Edmonds and M. Wise (1998), International Equity and Differentiation in Global Warming Policy. "Environmental and Resource Economics", vol. 12, pp. 2551.

Rubio, S. and A. Ulph (2001), A Simple Dynamic Model of International Environmental Agreements with a Stock Pollutant. Preliminary Version, University of Southampton.

Rundshagen, B. (2002), On the Formalization of Open Membership in Coalition Formation Games. Working Paper No. 318, University of Hagen.

Tahvonen, O. (1994), Carbon Dioxide Abatement as a Differential Game. "European Journal of Political Economy", vol. 10, pp. 685-705.

Tol, R. (2001), Climate Coalitions in an Integrated Assessment Model. "Computational Economics", vol. 18, pp. 159-172.

Tulkens, H., P. Chander, J.-P. van Ypersele and S. Willems (1999), The Kyoto Protocol. An Economic and Game Theoretic Interpretation. FEEM-Working Paper No. 72.99.

Yi, S.-S. (1997), Stable Coalition Structures with Externalities. "Games and Economic Behavior", vol. 20, pp. 201-237.

Yi, S.-S. and H. Shin (1995), Endogenous Formation of Coalitions in Oligopoly. Mimeo, Department of Economics, Dartmouth College. 


\section{Appendix}

The CLIMNEG World Simulation Model comprises the following equations:

$$
\begin{aligned}
\mathrm{Y}_{\mathrm{i}, \mathrm{t}} & =\mathrm{Z}_{\mathrm{i}, \mathrm{t}}+\mathrm{I}_{\mathrm{i}, \mathrm{t}}+\mathrm{Y}_{\mathrm{i}, \mathrm{t}} \mathrm{C}_{\mathrm{i}}\left(\mu_{\mathrm{i}, \mathrm{t}}\right)+\mathrm{Y}_{\mathrm{i}, \mathrm{t}} \mathrm{D}_{\mathrm{i}}\left(\Delta \mathrm{T}_{\mathrm{t}}\right) \\
\mathrm{Y}_{\mathrm{i}, \mathrm{t}} & =\mathrm{a}_{\mathrm{i}, \mathrm{t}} \mathrm{K}_{\mathrm{i}, \mathrm{t}}^{\gamma} \mathrm{L}_{\mathrm{i}, \mathrm{t}}^{1-\gamma} \\
\mathrm{C}_{\mathrm{i}}\left(\mu_{\mathrm{i}, \mathrm{t}}\right) & =\mathrm{b}_{\mathrm{i}, \mathrm{l}} \mu_{\mathrm{i}, \mathrm{t}}^{\mathrm{b}_{\mathrm{i}, 2}} \\
\mathrm{D}_{\mathrm{i}}\left(\Delta \mathrm{T}_{\mathrm{t}}\right) & =\theta_{\mathrm{i}, \mathrm{t}} \Delta \mathrm{T}^{\mathrm{i}_{\mathrm{i}, 2}} \\
\mathrm{~K}_{\mathrm{i}, \mathrm{t}+\mathrm{t}} & =\left[1-\delta_{\mathrm{K}}\right] \mathrm{K}_{\mathrm{i}, \mathrm{t}}+\mathrm{I}_{\mathrm{i}, \mathrm{t}} \quad \mathrm{K}_{\mathrm{i}, 0} \text { given } \\
\mathrm{E}_{\mathrm{i}, \mathrm{t}} & =\alpha_{\mathrm{i}, \mathrm{t}}\left[1-\mu_{\mathrm{i}, \mathrm{t}}\right] \mathrm{Y}_{\mathrm{i}, \mathrm{t}} \\
\mathrm{M}_{\mathrm{t}+1} & =\left[1-\delta_{\mathrm{M}}\right] \mathrm{M}_{\mathrm{t}}+\beta \sum_{\mathrm{i} \in \mathrm{N}} \mathrm{E}_{\mathrm{i}, \mathrm{t}} \quad \mathrm{M}_{0} \text { given } \\
\mathrm{F}_{\mathrm{t}} & =\frac{4.1 \ln \left(\mathrm{M}_{\mathrm{t}} / \mathrm{M}_{0}\right)}{\ln (2)}+\mathrm{F}_{\mathrm{t}}^{\mathrm{x}} \\
\mathrm{T}_{\mathrm{t}}^{0} & =\mathrm{T}_{\mathrm{t}-1}^{0}+\tau_{3}\left[\mathrm{~T}_{\mathrm{t}-1}^{\mathrm{a}}-\mathrm{T}_{\mathrm{t}-1}^{0}\right] \\
\mathrm{T}_{\mathrm{t}}^{\mathrm{a}} & =\mathrm{T}_{\mathrm{t}-1}^{\mathrm{a}}+\tau_{1}\left[\mathrm{~F}_{\mathrm{t}}-\lambda \mathrm{T}_{\mathrm{t}-1}^{\mathrm{a}}\right]-\tau_{2}\left[\mathrm{~T}_{\mathrm{t}-1}^{\mathrm{a}}-\mathrm{T}_{\mathrm{t}-1}^{0}\right] \\
\Delta \mathrm{T}_{\mathrm{t}} & =\frac{\mathrm{T}_{\mathrm{t}}^{\mathrm{a}}}{2.50}
\end{aligned}
$$

\section{List of Variables}

$\mathrm{Y}_{\mathrm{i}, \mathrm{t}} \quad$ production (billion $1990 \mathrm{US} \$$ )

$\mathrm{Z}_{\mathrm{i}, \mathrm{t}} \quad$ consumption (billion 1990 US\$)

$\mathrm{I}_{\mathrm{i}, \mathrm{t}} \quad$ investment (billion 1990 US\$)

$\mathrm{K}_{\mathrm{i}, \mathrm{t}} \quad$ capital stock (billion 1990 US\$)

$\mathrm{C}_{\mathrm{i}, \mathrm{t}} \quad$ cost of abatement (billion 1990 US\$)

$\mathrm{D}_{\mathrm{i}, \mathrm{t}} \quad$ damage from climate change (billion 1990 US\$)

$\mathrm{E}_{\mathrm{i}, \mathrm{t}} \quad$ carbon emissions (billion tons of $\mathrm{C}$ )

$\mu_{\mathrm{i}, \mathrm{t}} \quad$ emission abatement

$\mathrm{M}_{\mathrm{t}}$ atmospheric carbon concentration (billion tons of C)

$\mathrm{F}_{\mathrm{t}} \quad$ radiative forcing (Watt per $\mathrm{m}^{2}$ )

$\mathrm{F}_{\mathrm{t}}^{\mathrm{x}} \quad$ exogenous radiative forcing (Watt per $\mathrm{m}^{2}$ )

$\mathrm{T}_{\mathrm{t}}^{\mathrm{a}} \quad$ temperature increase in the atmosphere $\left({ }^{\circ} \mathrm{C}\right)$

$\mathrm{T}_{\mathrm{t}}^{0} \quad$ temperature increase in the deep ocean $\left({ }^{\circ} \mathrm{C}\right)$

$\Delta \mathrm{T}_{\mathrm{t}} \quad$ change of temperature increase in the atmosphere $\left({ }^{\circ} \mathrm{C}\right)$ 
Global Parameter Values

\begin{tabular}{llr}
\hline $\mathrm{a}_{\mathrm{i}, \mathrm{t}}$ & productivity & $\mathrm{RICE}$ \\
$\mathrm{L}_{\mathrm{i}, \mathrm{t}}$ & population & RICE \\
$\alpha_{\mathrm{i}, \mathrm{t}}$ & emission-output rate & $\mathrm{RICE}$ \\
$\delta_{\mathrm{K}}$ & capital depreciation rate & 0.10 \\
$\gamma$ & capital productivity parameter & 0.25 \\
$\beta$ & airborne fraction of carbon emissions & 0.64 \\
$\delta_{\mathrm{M}}$ & atmospheric carbon removal rate & 0.0833 \\
$\tau_{1}$ & parameter temperature relationship & 0.226 \\
$\tau_{2}$ & parameter temperature relationship & 0.44 \\
$\tau_{3}$ & parameter temperature relationship & 0.02 \\
$\lambda$ & parameter temperature relationship & 1.41 \\
$\mathrm{M}_{0}$ & initial carbon concentration & 590 \\
$\mathrm{~T}_{0}^{\mathrm{a}}$ & initial temperature atmosphere & 0.50 \\
$\mathrm{~T}_{0}^{0}$ & initial temperature deep ocean & 0.10 \\
\hline
\end{tabular}

Regional Parameter Values

\begin{tabular}{lccccc}
\hline & $\theta_{\mathrm{i}, 1}$ & $\theta_{\mathrm{i}, 2}$ & $\mathrm{~b}_{\mathrm{i}, 1}$ & $\mathrm{~b}_{\mathrm{i}, 2}$ & $\rho_{\mathrm{i}}$ \\
\hline USA & 0.01102 & 2.0 & 0.07 & 2.887 & 0.015 \\
JPN & 0.01174 & 2.0 & 0.05 & 2.887 & 0.015 \\
EU & 0.01174 & 2.0 & 0.05 & 2.887 & 0.015 \\
CHN & 0.01523 & 2.0 & 0.15 & 2.887 & 0.030 \\
FSU & 0.00857 & 2.0 & 0.15 & 2.887 & 0.015 \\
ROW & 0.02093 & 2.0 & 0.10 & 2.887 & 0.030 \\
\hline
\end{tabular}

Variables in 1990 (Reference Year)*

\begin{tabular}{lrrrrrrrr}
\hline & \multicolumn{1}{c}{$\mathrm{Y}_{\mathrm{i}}^{0}$} & $(\%)$ & \multicolumn{1}{c}{$\mathrm{K}_{\mathrm{i}}^{0}$} & $(\%)$ & \multicolumn{1}{c}{$\mathrm{L}_{\mathrm{i}}^{0}$} & \multicolumn{1}{c}{$(\%)$} & \multicolumn{1}{c}{$\mathrm{E}_{\mathrm{i}}^{0}$} & \multicolumn{1}{c}{$(\%)$} \\
\hline USA & $5,464.796$ & 25.9 & $14,262.510$ & 26.3 & 250.372 & 4.8 & 1.360 & 20.5 \\
JPN & $2,932.055$ & 13.9 & $8,442.250$ & 15.6 & 123.537 & 2.4 & 0.292 & 10.9 \\
EU & $6,828.042$ & 32.4 & $18,435.710$ & 34.0 & 366.497 & 7.0 & 0.872 & 28.9 \\
CHN & 370.024 & 1.8 & $1,025.790$ & 1.9 & $1,133.683$ & 21.5 & 0.669 & 3.0 \\
FSU & 855.207 & 4.1 & $2,281.900$ & 4.2 & 289.324 & 5.5 & 1.066 & 6.8 \\
ROW & $4,628.621$ & 22.0 & $9,842.220$ & 18.1 & $3,102.689$ & 58.9 & 1.700 & 29.9 \\
\hline World & $21,078.750$ & 100.0 & $54,290.380$ & 100.0 & $5,266.100$ & 100.0 & 5.959 & 100.0 \\
\hline
\end{tabular}

* $\quad \mathrm{Y}_{\mathrm{i}}^{0}$ and $\mathrm{K}_{\mathrm{i}}^{0}$ million US\$, $\mathrm{L}_{\mathrm{i}}^{0}$ million people and $\mathrm{E}_{\mathrm{i}}^{0}$ giga tons. 
The first order conditions for computing valutations are derived from the following maximization problem:

$$
\begin{gathered}
\max _{\left\{\mathrm{I}_{\mathrm{i}, \mathrm{t}}, \mu_{\mathrm{i}, t}\right\}_{\mathrm{i} \in \mathrm{c}^{\mathrm{k}}, \mathrm{t}=0, \ldots, \Omega}} \sum_{\mathrm{i} \in \mathrm{c}^{\mathrm{k}}} \sum_{\mathrm{t}=0}^{\Omega} \frac{\mathrm{Z}_{\mathrm{i}, \mathrm{t}}}{\left[1+\rho_{\mathrm{i}}\right]^{\mathrm{t}}} \\
\text { s.t. } \sum_{\mathrm{i} \in \mathrm{c}^{\mathrm{k}}} \mathrm{F}_{\mathrm{i}, \mathrm{t}}\left(\mathrm{K}_{\mathrm{i}, \mathrm{t}}\right)\left[1-\mathrm{C}_{\mathrm{i}}\left(\mu_{\mathrm{i}, \mathrm{t}}\right)-\mathrm{D}_{\mathrm{i}}\left(\mathrm{G}\left(\mathrm{M}_{\mathrm{t}}\right)\right)\right]=\sum_{\mathrm{i} \in \mathrm{c}^{\mathrm{k}}}\left[\mathrm{Z}_{\mathrm{i}, \mathrm{t}}+\mathrm{I}_{\mathrm{i}, \mathrm{t}}\right] \\
\mathrm{M}_{\mathrm{t}+1}=\left[1-\delta_{\mathrm{M}}\right] \mathrm{M}_{\mathrm{t}}+\beta \sum_{\mathrm{i} \in \mathrm{c}^{\mathrm{k}}} \alpha_{\mathrm{i}, \mathrm{t}}\left[1-\mu_{\mathrm{i}, \mathrm{t}}\right] \mathrm{F}_{\mathrm{i}, \mathrm{t}}\left(\mathrm{K}_{\mathrm{i}, \mathrm{t}}\right)+\beta \sum_{\mathrm{j} \notin \mathrm{c}^{\mathrm{k}}} \overline{\mathrm{E}}_{\mathrm{j}, \mathrm{t}}
\end{gathered}
$$

This gives rise to two first oder conditions of region $\mathrm{i}$ being a member of coalition $\mathrm{c}^{\mathrm{k}}$ in coalition structure $\mathrm{c}$ at time $\mathrm{t}$ :

$$
\begin{gathered}
\frac{1}{\left[1+\rho_{\mathrm{i}}\right]^{\mathrm{t}}} \frac{\mathrm{C}_{\mathrm{i}}{ }^{\prime}\left(\mu_{\mathrm{i}, \mathrm{t}}\right)}{\alpha_{\mathrm{i}, \mathrm{t}}}=\beta \sum_{\mathrm{i} \in \mathrm{c}^{\mathrm{k}}} \sum_{\tau=\mathrm{t}+1}^{\Omega} \frac{\mathrm{F}_{\mathrm{i}, \tau}\left(\mathrm{K}_{\mathrm{i}, \tau}\right) \mathrm{D}_{\mathrm{i}, \tau}{ }^{\prime}\left(\Delta \mathrm{T}_{\tau}\right)}{\left[1+\rho_{\mathrm{i}}\right]^{\tau}} \mathrm{G}_{\tau}^{\prime}\left(\mathrm{M}_{\tau}\right)\left[1-\delta_{\mathrm{M}}\right]^{\tau-\mathrm{t}-1} \\
\rho_{\mathrm{i}}=\mathrm{F}_{\mathrm{i}, \mathrm{t}}{ }^{\prime}\left(\mathrm{K}_{\mathrm{i}, \mathrm{t}}\right)\left\{1-\mathrm{C}_{\mathrm{i}}\left(\mu_{\mathrm{i}, \mathrm{t}}\right)-\mathrm{D}_{\mathrm{i}}\left(\Delta \mathrm{T}_{\mathrm{t}}\right)-\left[1-\mu_{\mathrm{i}, \mathrm{t}}\right] \frac{\mathrm{C}_{\mathrm{i}}^{\prime}\left(\mu_{\mathrm{i}, \mathrm{t}}\right)}{\left[1+\rho_{\mathrm{i}}\right]^{\mathrm{t}}}\right\}-\delta_{\mathrm{K}}
\end{gathered}
$$




\section{Tables and Figures}

Table 2: Stable Coalition Structures in the No Transfer Case

\begin{tabular}{|c|c|c|c|c|c|c|c|c|c|c|c|c|c|}
\hline \multirow{3}{*}{\begin{tabular}{|c} 
No. \\
(1)
\end{tabular}} & \multirow{3}{*}{$\begin{array}{c}\text { Coalition Structure } \\
\text { (2) }\end{array}$} & \multirow{2}{*}{\multicolumn{2}{|c|}{$\begin{array}{l}\mathrm{OM} \\
(3)\end{array}$}} & \multirow{2}{*}{\multicolumn{2}{|c|}{$\begin{array}{c}\text { EM-MV } \\
(4)\end{array}$}} & \multirow{2}{*}{\multicolumn{2}{|c|}{$\begin{array}{c}\text { EM-UV } \\
(5)\end{array}$}} & \multirow{3}{*}{$\begin{array}{l}\text { Welfare } \\
\text { (6) }\end{array}$} & \multirow{3}{*}{$\begin{array}{c}\text { DEX } \\
(7)\end{array}$} & \multirow{3}{*}{$\begin{array}{c}\text { Concentration } \\
\text { (8) }\end{array}$} & \multirow{3}{*}{$\begin{array}{l}\text { DEX } \\
(9)\end{array}$} & \multirow{3}{*}{$\begin{array}{c}\text { Emissions } \\
(10)\end{array}$} & \multirow{3}{*}{$\begin{array}{l}\text { DEX } \\
(11)\end{array}$} \\
\hline & & & & & & & & & & & & & \\
\hline & & $\mathrm{S}$ & M & $\mathrm{S}$ & $\mathrm{M}$ & $\mathrm{S}$ & $\mathrm{M}$ & & & & & & \\
\hline 203 & $\{$ USA,JPN,EU,CHN,FSU,ROW\} & $\mathrm{n}$ & $\mathrm{n}$ & $\mathrm{n}$ & $\mathrm{n}$ & $\mathrm{n}$ & $\mathrm{n}$ & 339830.726 & 0.00 & & 0.00 & & 0.00 \\
\hline 26 & $\{$ USA,FSU,ROW $\},\{\mathrm{JPN}\},\{\mathrm{EU}\},\{\mathrm{CHN}\}$ & $\mathrm{n}$ & $\mathrm{n}$ & $\mathrm{n}$ & $\mathrm{n}$ & $\mathrm{y}$ & $\mathrm{y}$ & 339134.977 & 0.21 & & 78.35 & & 59.03 \\
\hline 156 & $\{\mathbf{U S A}, \mathbf{J P N}, \mathbf{R O W}\},\{\mathrm{EU}\},\{\mathrm{CHN}\},\{\mathrm{FSU}\}$ & $\mathrm{n}$ & $\mathrm{n}$ & $\mathrm{n}$ & $\mathrm{n}$ & $\mathrm{y}$ & $\mathrm{y}$ & 339105.160 & 0.21 & & 80.65 & 1240.635 & 60.59 \\
\hline 155 & $\{\mathbf{U S A}, \mathbf{J P N}\},\{\mathbf{E U}, \mathbf{R O W}\},\{\mathrm{CHN}\},\{\mathrm{FSU}\}$ & - & $\mathrm{n}$ & - & $\mathrm{y}$ & - & $\mathrm{y}$ & 339088.903 & 0.22 & & 81.38 & 1245.867 & 61.27 \\
\hline 4 & $\{\mathbf{E U}, \mathbf{R O W}\},\{\mathrm{USA}\},\{\mathrm{JPN}\},\{\mathrm{CHN}\},\{\mathrm{FSU}\}$ & $\mathrm{n}$ & $\mathrm{n}$ & $\mathrm{y}$ & $\mathrm{n}$ & $\mathrm{y}$ & $\mathrm{n}$ & 339077,348 & 0.22 & & 81.63 & 1247.764 & 61.52 \\
\hline 20 & $\{\mathbf{J P N}, \mathbf{F S U}, \mathbf{R O W}\},\{\mathrm{USA}\},\{\mathrm{EU}\},\{\mathrm{CHN}\}$ & $\mathrm{n}$ & $\mathrm{n}$ & $\mathrm{n}$ & $\mathrm{n}$ & $\mathrm{y}$ & $\mathrm{y}$ & 339019.573 & 0.24 & 3648.097 & 90.71 & 1299.488 & 68.21 \\
\hline 6 & $\{\mathbf{U S A}, \mathbf{R O W}\},\{\mathrm{JPN}\},\{\mathrm{EU}\},\{\mathrm{CHN}\},\{\mathrm{FSU}\}$ & $\mathrm{n}$ & $\mathrm{n}$ & $\mathrm{y}$ & $\mathrm{y}$ & $\mathrm{y}$ & $\mathrm{y}$ & 339018.374 & 0.24 & 3622.360 & 89.36 & 1292.177 & 67.27 \\
\hline 153 & $\{\mathbf{U S A}, \mathbf{J P N}\},\{\mathbf{F S U}, \mathbf{R O W}\},\{\mathrm{EU}\},\{\mathrm{CHN}\}$ & - & $\mathrm{n}$ & - & $\mathrm{y}$ & - & $\mathrm{y}$ & 338907.856 & 0.27 & 3839.731 & 100.73 & 1358.172 & 75.81 \\
\hline 2 & $\{\boldsymbol{F S U}, \boldsymbol{R O} \boldsymbol{W}\},\{U S A\},\{J P N\},\{E U\},\{C H N\}$ & $\mathrm{n}$ & $\mathrm{n}$ & $\mathrm{y}$ & $\mathrm{n}$ & $\mathrm{y}$ & $\mathrm{n}$ & 338895,952 & 0.28 & & 100.99 & 1360.210 & 76.07 \\
\hline 5 & $\{\mathbf{J P N}, \mathbf{R O W}\},\{\mathrm{USA}\},\{\mathrm{EU}\},\{\mathrm{CHN}\},\{\mathrm{FSU}\}$ & $\mathrm{n}$ & $\mathrm{n}$ & $\mathrm{y}$ & $\mathrm{y}$ & $\mathrm{y}$ & $\mathrm{y}$ & & 0.28 & & 103.79 & & 77.78 \\
\hline 196 & $\{\mathbf{U S A}, \mathbf{J P N}, \mathbf{E U}, \mathbf{F S U}\},\{\mathrm{CHN}\},\{\mathrm{ROW}\}$ & $\mathrm{n}$ & $\mathrm{n}$ & $\mathrm{n}$ & $\mathrm{n}$ & $\mathrm{n}$ & $\mathrm{n}$ & 338149.623 & 0.49 & 4508.541 & 135.69 & 1575.837 & 103.98 \\
\hline 87 & $\{$ JPN,EU,FSU $\},\{U S A\},\{\mathrm{CHN}\},\{\mathrm{ROW}\}$ & $\mathrm{n}$ & $\mathrm{n}$ & $\mathrm{n}$ & $\mathrm{n}$ & $\mathrm{n}$ & $\mathrm{n}$ & & 0.51 & & 136.84 & & 105.17 \\
\hline 1 & $\{\mathrm{USA}\},\{\mathrm{JPN}\},\{\mathrm{EU}\},\{\mathrm{CHN}\},\{\mathrm{FSU}\},\{\mathrm{ROW}\}$ & $\mathrm{y}$ & $\mathrm{n}$ & $\mathrm{y}$ & $\mathrm{n}$ & $\mathrm{y}$ & $\mathrm{n}$ & 338059.826 & 0.52 & 4550.202 & 137.87 & 1593.398 & 106.26 \\
\hline
\end{tabular}


Table 3: Stable Coalition Structures in the Transfer Case

\begin{tabular}{|c|c|c|c|c|c|c|c|c|c|c|c|c|c|}
\hline \multirow{2}{*}{$\begin{array}{l}\text { No. } \\
(1)\end{array}$} & \multirow{2}{*}{$\begin{array}{l}\text { Coalition Structure } \\
\text { (2) }\end{array}$} & \multicolumn{2}{|c|}{$\begin{array}{l}\mathrm{OM} \\
(3)\end{array}$} & \multicolumn{2}{|c|}{$\begin{array}{c}\text { EM-MV } \\
(4)\end{array}$} & \multicolumn{2}{|c|}{$\begin{array}{c}\text { EM-UV } \\
(5)\end{array}$} & \multirow{2}{*}{$\begin{array}{l}\text { Welfare } \\
\text { (6) }\end{array}$} & \multirow{2}{*}{$\begin{array}{c}\text { DEX } \\
(7)\end{array}$} & \multirow{2}{*}{$\begin{array}{c}\text { Concentration } \\
(8)\end{array}$} & \multirow{2}{*}{$\begin{array}{l}\text { DGX } \\
(9)\end{array}$} & \multirow{2}{*}{$\begin{array}{c}\text { Emissions } \\
(10)\end{array}$} & \multirow{2}{*}{$\begin{array}{l}\text { DGX } \\
(11)\end{array}$} \\
\hline & & & $\mathrm{M}$ & $\mathrm{S}$ & $\mathrm{M}$ & $\mathrm{S}$ & $\mathrm{M}$ & & & & & & \\
\hline 203 & $\{$ USA,JPN,EU,CHN,FSU,ROW\} & $\mathrm{n}$ & $\mathrm{n}$ & $\mathrm{n}$ & $\mathrm{n}$ & $\mathrm{n}$ & $n$ & 339830.726 & 0.00 & 1912.907 & 0.00 & 772.529 & 0.00 \\
\hline 31 & $\{\mathbf{U S A}, \mathbf{R O W}\},\{\mathbf{E U}, \mathbf{C H N}\},\{\mathrm{JPN}\},\{\mathrm{FSU}\}$ & - & $\mathrm{n}$ & - & $\mathrm{y}$ & - & $\mathrm{y}$ & 339378.119 & 0.13 & 3185.380 & 66.52 & 1157.776 & 49.87 \\
\hline 46 & $\{\mathbf{J P N}, \mathbf{C H N}\},\{\mathbf{E U}, \mathbf{R O W}\},\{\mathrm{USA}\},\{\mathrm{FSU}\}$ & - & $\mathrm{y}$ & - & $\mathrm{y}$ & - & $\mathrm{y}$ & 339265.727 & 0.17 & 3270.385 & 70.96 & 1184.793 & 53.37 \\
\hline 28 & $\{\mathbf{E U}, \mathbf{C H N}\},\{\mathbf{F S U}, \mathbf{R O W}\},\{\mathrm{USA}\},\{\mathrm{JPN}\}$ & - & $\mathrm{n}$ & 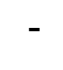 & $\mathrm{y}$ & 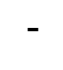 & $\mathrm{y}$ & 339249.498 & 0.17 & 3420.970 & 78.84 & 1229.317 & 59.13 \\
\hline 30 & $\{\mathbf{J P N}, \mathbf{R O W}\},\{\mathbf{E U}, \mathbf{C H N}\},\{\mathrm{USA}\},\{\mathrm{FSU}\}$ & - & $\mathrm{n}$ & - & $\mathrm{y}$ & - & $\mathrm{y}$ & 339234.553 & 0.18 & 3477.597 & 81.80 & 1243.367 & 60.95 \\
\hline 4 & $\{\mathbf{E U}, \mathbf{R O W}\},\{\mathrm{USA}\},\{\mathrm{JPN}\},\{\mathrm{CHN}\},\{\mathrm{FSU}\}$ & $\mathrm{y}$ & $\mathrm{n}$ & $\mathrm{y}$ & $\mathrm{n}$ & $\mathrm{y}$ & $\mathrm{n}$ & 339077,348 & 0.22 & 3474.433 & 81.63 & 1247.764 & 61.52 \\
\hline 117 & $\{$ USA, $\mathbf{E U}\},\{\mathbf{C H N}, \mathbf{R O W}\},\{\mathrm{JPN}\},\{\mathrm{FSU}\}$ & - & $\mathrm{n}$ & - & $\mathrm{y}$ & - & $\mathrm{y}$ & 339054.455 & 0.23 & 3971.249 & 107.60 & 1380.521 & 78.70 \\
\hline 3 & $\{\mathbf{C H N}, \mathbf{R O W}\},\{\mathrm{USA}\},\{\mathrm{JPN}\},\{\mathrm{EU}\},\{\mathrm{FSU}\}$ & $\mathrm{y}$ & $\mathrm{n}$ & $\mathrm{y}$ & $\mathrm{n}$ & $\mathrm{y}$ & $\mathrm{n}$ & 339026.549 & 0.24 & 3986.954 & 108.42 & 1386.628 & 79.49 \\
\hline 6 & $\{$ USA,ROW $\},\{\mathrm{JPN}\},\{\mathrm{EU}\},\{\mathrm{CHN}\},\{\mathrm{FSU}\}$ & $\mathrm{y}$ & $\mathrm{n}$ & $\mathrm{y}$ & $\mathrm{n}$ & $\mathrm{y}$ & $\mathrm{n}$ & 339018.374 & 0.24 & 3622.360 & 89.36 & 1292.177 & 67.27 \\
\hline 2 & $\{$ FSU, ROW $\},\{\mathrm{USA}\},\{\mathrm{JPN}\},\{\mathrm{EU}\},\{\mathrm{CHN}\}$ & $\mathrm{y}$ & $\mathrm{n}$ & $\mathrm{y}$ & $\mathrm{n}$ & $\mathrm{y}$ & $\mathrm{n}$ & 338895.952 & 0.28 & 3844.839 & 100.99 & 1360.210 & 76.07 \\
\hline 5 & $\{\mathbf{J P N}, \mathbf{R O W}\},\{\mathrm{USA}\},\{\mathrm{EU}\},\{\mathrm{CHN}\},\{\mathrm{FSU}\}$ & $\mathrm{y}$ & $\mathrm{n}$ & $\mathrm{y}$ & $\mathrm{n}$ & $\mathrm{y}$ & $\mathrm{n}$ & 338882.175 & 0.28 & 3898.367 & 103.79 & 1373.392 & 77.78 \\
\hline 196 & $\{$ USA,JPN,EU,FSU $\},\{\mathrm{CHN}\},\{\mathrm{ROW}\}$ & $\mathrm{n}$ & $\mathrm{n}$ & $\mathrm{n}$ & $\mathrm{n}$ & $\mathrm{n}$ & $\mathrm{n}$ & 338149.623 & 0.49 & 4508.541 & 135.69 & 1575.837 & 103.98 \\
\hline 87 & $\{\mathbf{J P N}, \mathbf{E U}, \mathbf{F S U}\},\{\mathrm{USA}\},\{\mathrm{CHN}\},\{\mathrm{ROW}\}$ & $\mathrm{n}$ & $\mathrm{n}$ & $\mathrm{n}$ & $\mathrm{n}$ & $\mathrm{n}$ & $\mathrm{n}$ & 338111.881 & 0.51 & 4530.523 & 136.84 & 1584.988 & 105.17 \\
\hline 1 & $\{\mathrm{USA}\},\{\mathrm{JPN}\},\{\mathrm{EU}\},\{\mathrm{CHN}\},\{\mathrm{FSU}\},\{\mathrm{ROW}\}$ & $\mathrm{y}$ & $\mathrm{n}$ & $\mathrm{y}$ & $\mathrm{n}$ & $\mathrm{y}$ & $\mathrm{n}$ & 338059.826 & 0.52 & 4550.202 & 137.87 & 1593.398 & 106.26 \\
\hline
\end{tabular}


Figure 1: World Carbon Emissions $\left(\mathrm{GtCO}_{2}\right)$

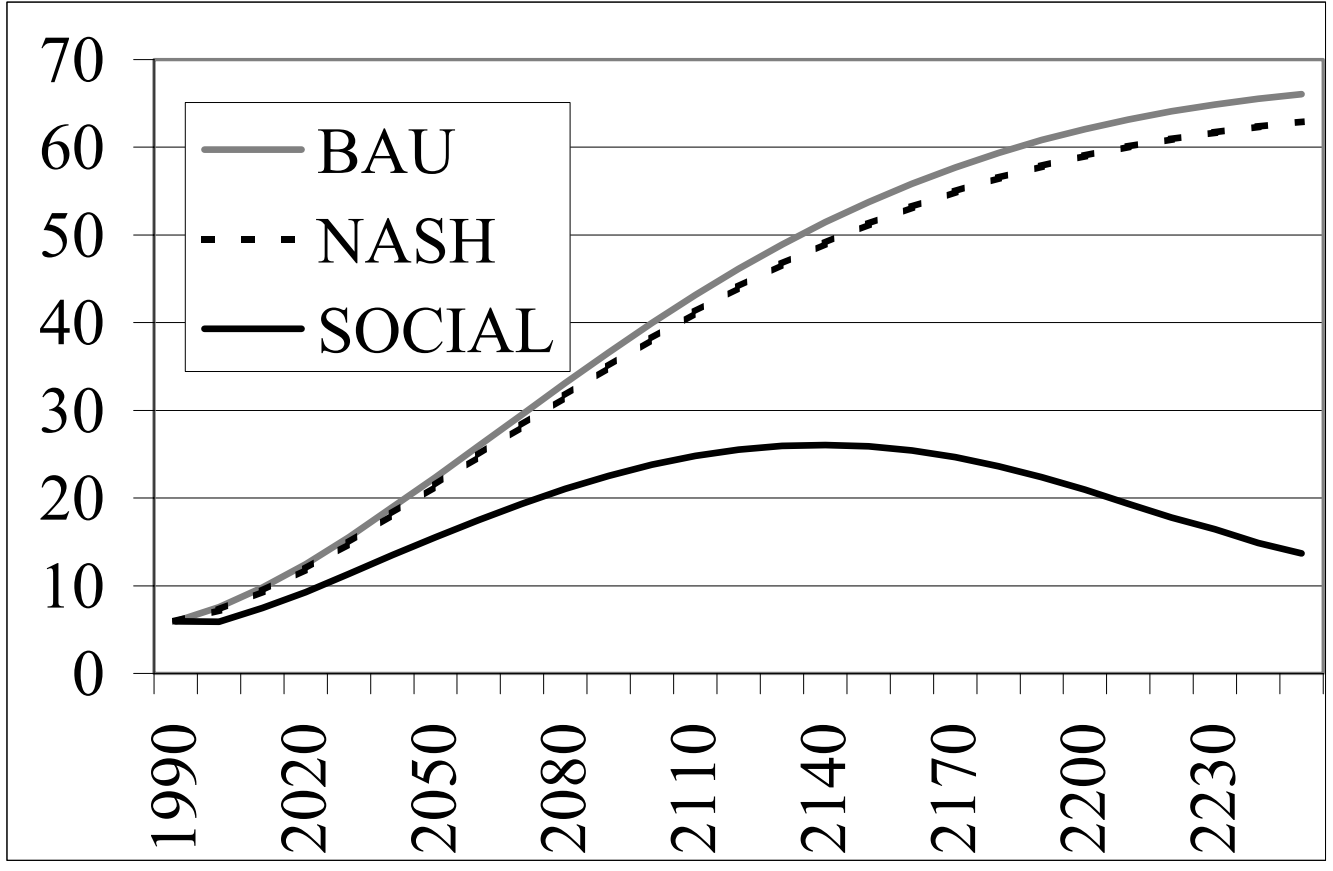

Figure 2: Atmospheric Carbon Concentration $\left(\mathrm{GtCO}_{2}\right)$

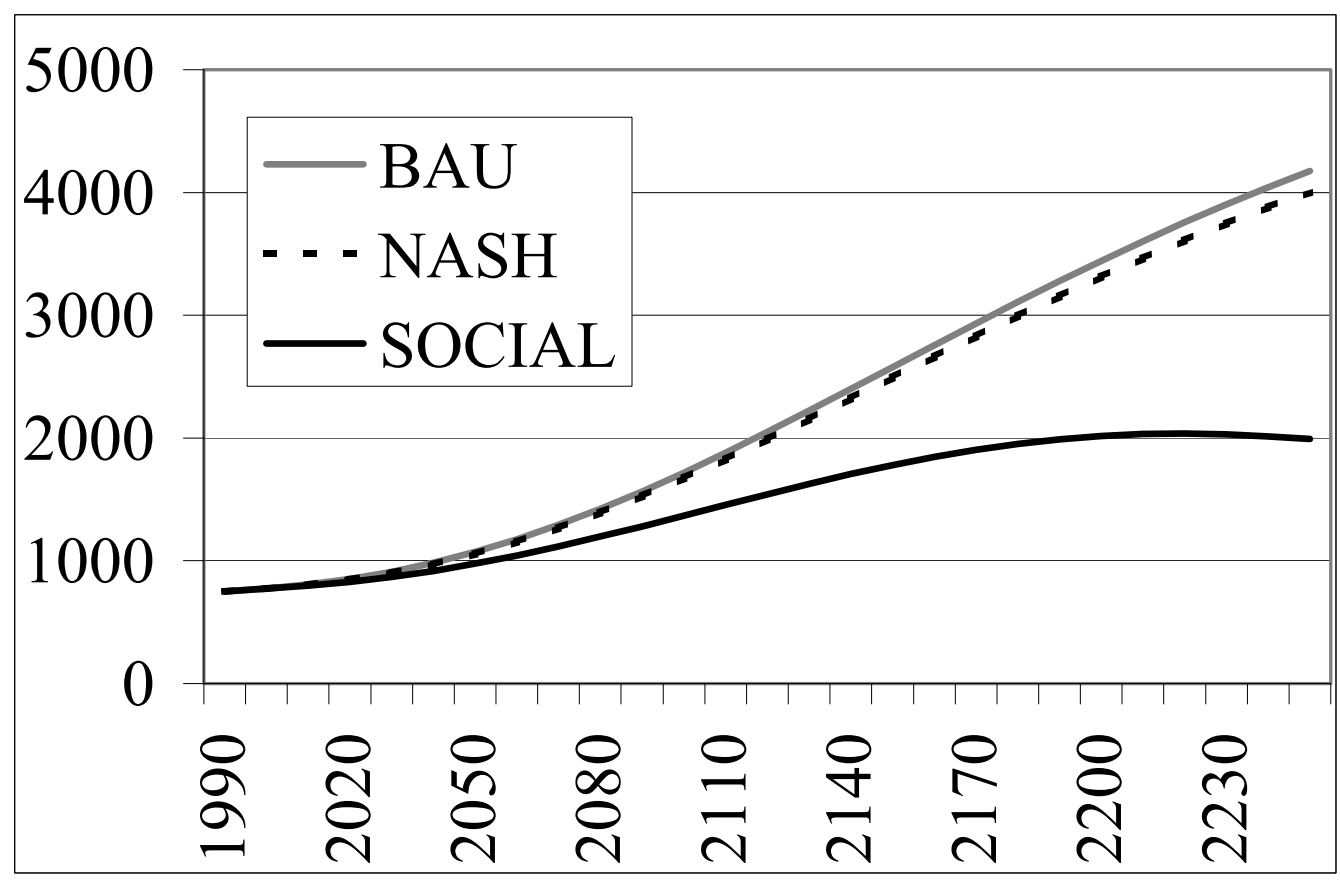


Figure 3: World GDP Composition in NASH scenario*

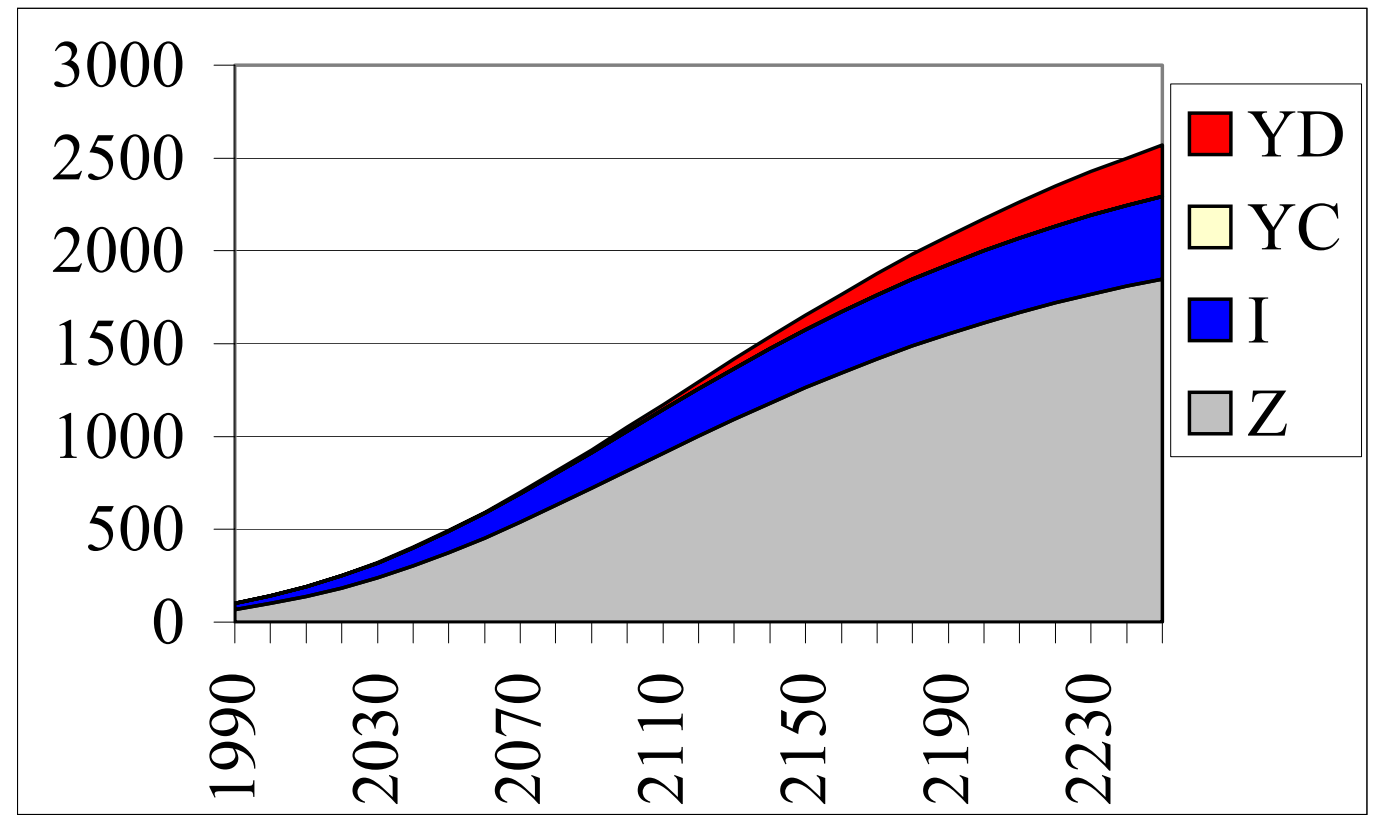

* $\mathrm{Y}=\mathrm{Z}+\mathrm{I}+\mathrm{YC}+\mathrm{YD}$ as in equation (1). World production in 1990 is nomalized to 100.

Figure 4: World GDP Composition in SOCIAL scenario*

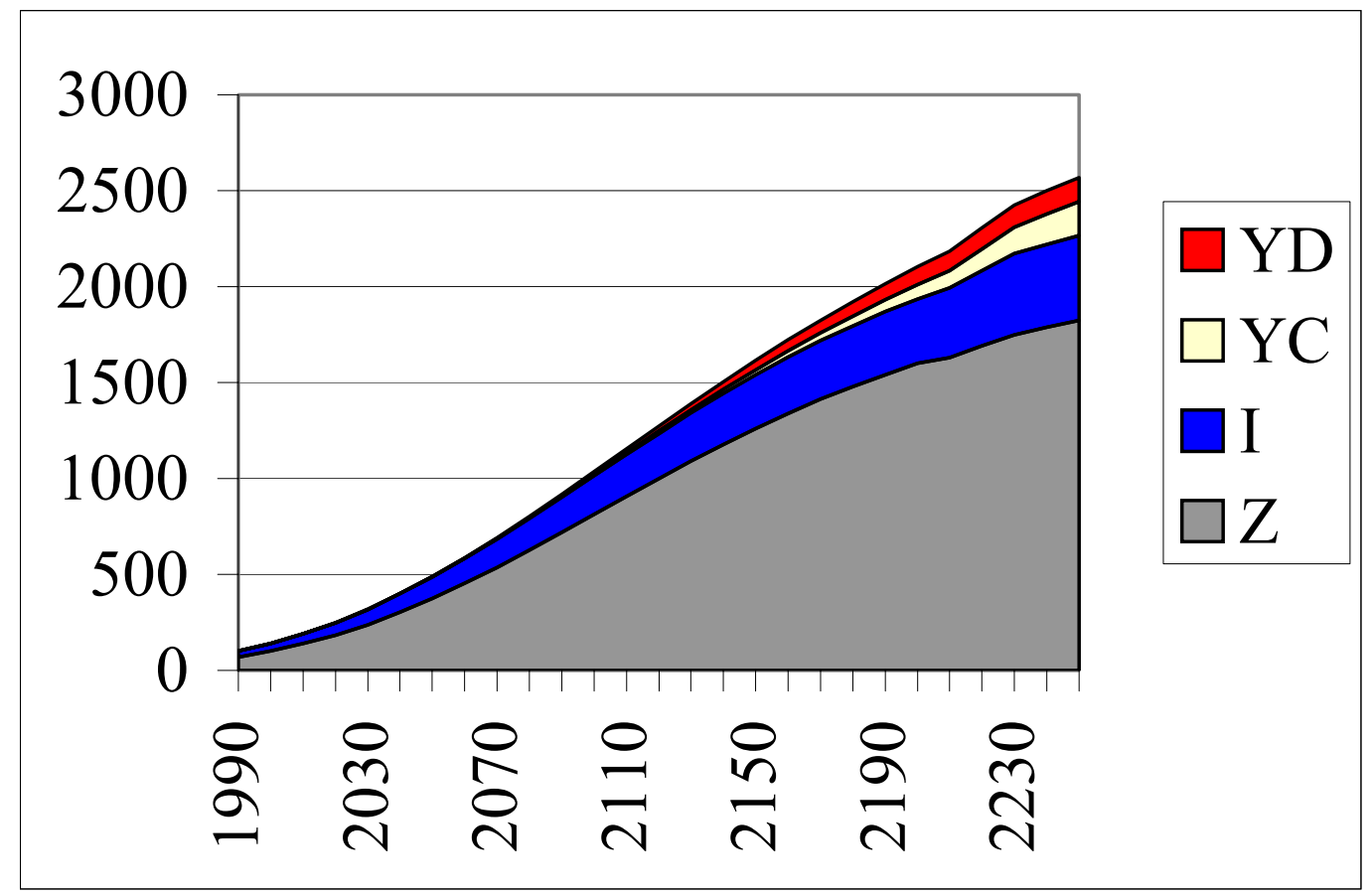

* $\mathrm{Y}=\mathrm{Z}+\mathrm{I}+\mathrm{YC}+\mathrm{YD}$ as in equation (1). World production in 1990 is nomalized to 100. 
The Center for Economic Studies (CES) is the research division of the Department of Economics of the Katholieke Universiteit Leuven. The CES research department employs some 100 people. The division Energy, Transport \& Environment (ETE) currently consists of about 15 full time researchers. The general aim of ETE is to apply state of the art economic theory to current policy issues at the Flemish, Belgian and European level. An important asset of ETE is its extensive portfolio of numerical partial and general equilibrium models for the assessment of transport, energy and environmental policies.

\section{ETE WORKING PAPER SERIES 2003}

$n^{\circ} 2003-18$

$n^{\circ} 2003-17$

$n^{\circ} 2003-16$

$n^{\circ} 2003-15$

$n^{\circ} 2003-14$

$n^{\circ} 2003-13$

$n^{\circ} 2003-12$

$n^{\circ} 2003-11$

$n^{\circ} 2003-10$

$n^{\circ} 2003-09$

$n^{\circ} 2003-08$

$n^{\circ} 2003-07$

$n^{\circ} 2003-06$
Eyckmans J., Finus M. (2003), New Roads to International Environmental Agreements: The Case of Global Warming*

Eyckmans J., Finus M. (2003), Coalition Formation in a Global Warming Game: How the Design of Protocols Affects the Success of Environmental Treaty-Making

Eyckmans J., Schokkaert E. (2003), An "Ideal" Normative Theory for Greenhouse Negociations

Bigano A., Proost S. (2003), The opening of the European electricity market and environmental policy: does the degree of competition matter?

Pepermans G., Willems B. (2003), Regulating transmission in a spatial oligopoly: a numerical illustration for Belgium

Eyckmans J., Pepermans G. (2003), Is er toekomst voor kernenergie in België?

Franckx L. and D'Amato A. (2003), Environmental policy as a multi-task principal-agent problem

Proost S. And Van Dender K. (2003), Marginal Social Cost Pricing For All Transport Modes And The Effects Of Modal Budget Constraints

Mayeres I., Van Regemorter D. (2003), Modelling the health related benefits of environmental policies - a CGE ANALYSIS for the EU countries with GEM-E3

De Borger B., Proost S., Van Dender K. (2003), Congestion And Tax Competition In A Parallel Network

Pepermans G., Driesen J., Haeseldonckx D., D'haeseleer W. and Belmans R. (2003), Distributed generation: definition, benefits and issues

Moons E., The development and application of economic valuation techniques and their use in environmental policy - A survey

Muys B., Deckmyn G., Moons E., Quijano J.G., Proost S. and Ceulemans R. (2003), An integrated decision support tool for the prediction and evaluation of efficiency, environmental impact and total social cost of forestry projects in the framework of the Kyoto protocol 